\title{
The Web 2.0 Revolution: Using technology to shape standard- based instruction
}

Joern-Timo Riepel

West Virginia University

Follow this and additional works at: https://researchrepository.wvu.edu/etd

\section{Recommended Citation}

Riepel, Joern-Timo, "The Web 2.0 Revolution: Using technology to shape standard-based instruction" (2011). Graduate Theses, Dissertations, and Problem Reports. 4772.

https://researchrepository.wvu.edu/etd/4772

This Thesis is protected by copyright and/or related rights. It has been brought to you by the The Research Repository @ WVU with permission from the rights-holder(s). You are free to use this Thesis in any way that is permitted by the copyright and related rights legislation that applies to your use. For other uses you must obtain permission from the rights-holder(s) directly, unless additional rights are indicated by a Creative Commons license in the record and/ or on the work itself. This Thesis has been accepted for inclusion in WVU Graduate Theses, Dissertations, and Problem Reports collection by an authorized administrator of The Research Repository @ WVU. For more information, please contact researchrepository@mail.wvu.edu. 
The Web 2.0 Revolution: Using technology to shape standard-based instruction

$$
\text { Joern-Timo Riepel }
$$

\author{
Thesis submitted to the \\ Eberly College of Arts and Sciences \\ at West Virginia University \\ in partial fulfillment of the requirements \\ for the degree of
}



Cynthia Chalupa, Ph.D., Chair Xiangying Jiang, Ph.D. Johan Seynnaeve, Ph.D.

Department of Foreign Languages

Morgantown, West Virginia 2011 


\title{
ABSTRACT
}

\section{The Web 2.0 Revolution: Using technology to shape content-based instruction}

\author{
Joern-Timo Riepel
}

\begin{abstract}
Different Web 2.0 applications, such as weblogs, podcasts, wikis, and twitter have revolutionized the way people interact online and opened a path to a new way of global masscommunication for every internet user. Web 2.0 applications have also proved to enhance foreign language instruction in terms of learner motivation, collaborative learning processes, time-and space independence for students across classroom boundaries, and chances for authentic language use and perception. This thesis demonstrates the uses of Web 2.0 to enhance standards-based foreign language education and address each of the five C's using 21st-century technologies. By implementing Web 2.0 as an instructional tool, teachers can align their courses with the ACTFL standards and the modes of communication through which they can best be communicated. The thesis outlines a thematic unit of instruction, which demonstrates the use of Web 2.0 in teaching the standards and modes of communication and also functions as a ready-to-use sequence in class.
\end{abstract}


Ricarda and Hans-Albert Riepel for their never-ending inspiration 


\section{Acknowledgements}

First of all, I would like to thank the chair of my committee, Dr. Cynthia Chalupa, for her continuous and valuable feedback on the various drafts I handed in. I also want to thank her for being a major source of inspiration in both my professional development as a foreign language teacher, and my scholarly development. I could not have done it without her.

I also want to thank Dr. Jiang and Dr. Xiangying Jiang and Dr. Johan Seynnaeve for their help, feedback and support during the process of creating this thesis.

I would also like to thank Reinhard Donath for inspiring me to choose the field of Web 2.0-based foreign language teaching as a specialization in my studies and as my major field of professional interest. I would furthermore like to thank Dr. Des. Maike Engelhardt for guiding me towards my studies at West Virginia University and being of major support and guidance throughout my studies.

I would also like to thank my fiancé Amanda Kaye Miller for her love and never-ending patience and support during the creation of this thesis. I do not even want to imagine writing this thesis without her 'You can do it!'s and 'Get it done!'s. Finally, I would like to thank my friends and colleagues here at WVU who made these two years in West Virginia an unforgettable one-time experience. 
Acknowledgements ............................................................................................ iv

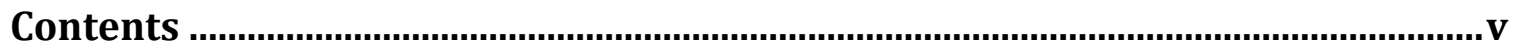



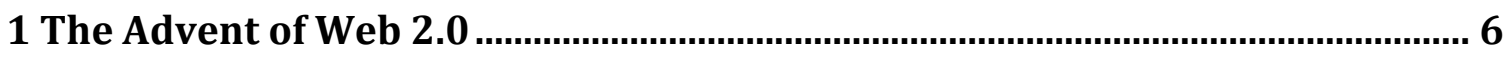

1.1 Web 1.0

1.2 Turning communication upside down: Web 2.0 and its features.......................... 13

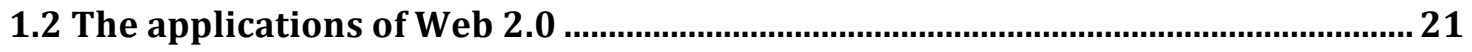

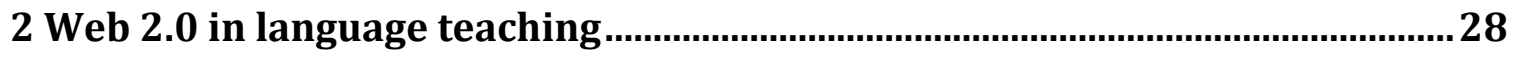

\subsection{The History of Computer-Assisted Language Learning}

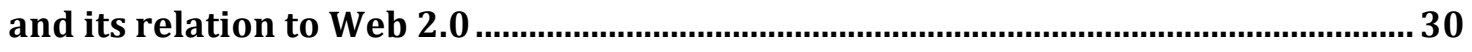

2.2 Web 2.0 applications in the teaching of language skills ..................................... 37

2.3 Motivating Factors of Web 2.0 in the Classroom ................................................... 52

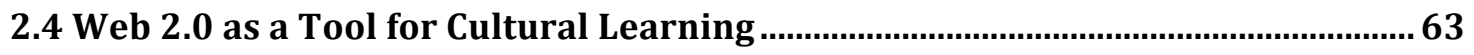

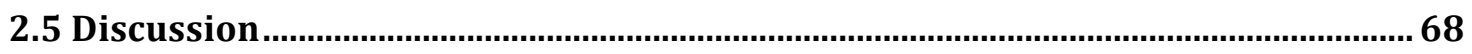

3 Relating Web 2.0 to the Standards for Foreign Language Learning .................74

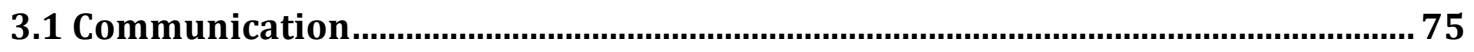

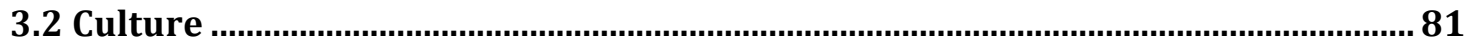

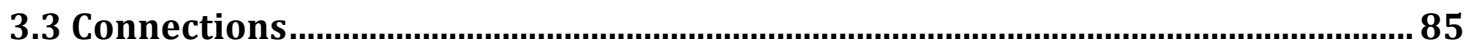

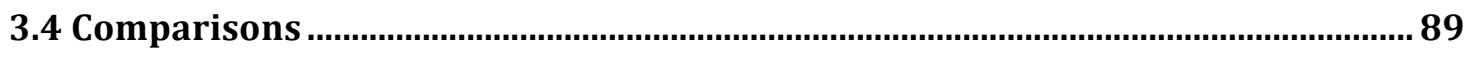




4. The standards-based Foreign Language Instruction and Web 2.0:

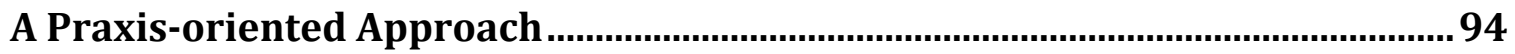



4.2 Voicethread.com, tinychat.com, and xtranormal.com .........................................102

4.3 Web 2.0: Concrete Examples for Classroom Teaching............................................109

5. Conclusion, limitations, and implications for future research ....................... 128

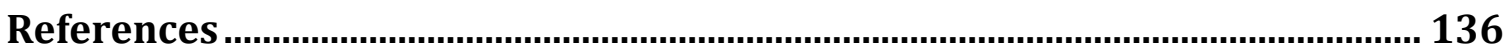



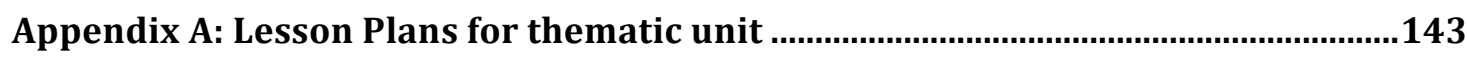

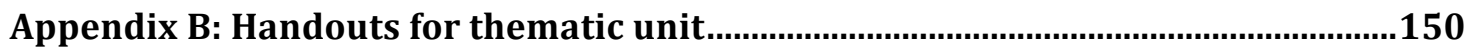

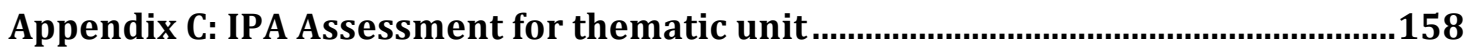

Appendix D: Rubrics for IPA interpersonal and presentational ..............................162

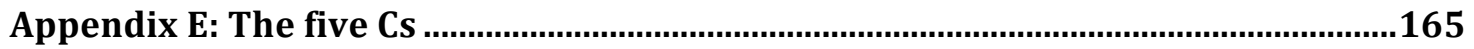




\section{Introduction}

After almost twenty years of serving people as a means of communication, today's internet has evolved from being a medium of global availability and occasional usage, to an everyday tool utilized in many countries all over the world. Since more and more people have access to online resources, the internet has become one of the leading forms of media that people interact through and with on an everyday basis. One of the effects on our everyday life is that we can share information at a pace that pre-internet human communication could only dream of. This pace of communication has had various effects on our everyday communication. For example, more and more people read their daily news on a website rather than in the daily newspaper. The speed at which news is made available online has deemed printmedia quickly outdated, carrying yesterday's news and the opinions of a few editors. The internet has also changed the way we look at news. Instead of being limited to the opinion of local or national news, global sources are available online for everyone.

While the internet started out as "a vast network of linking computers all over the world" (Marcos, 1994, p.2), it has become not only a network of machines, but also a network of 
people and their thoughts, opinions, values and cultures. This can be exemplified not only by how we perceive our daily news online, but also by users' daily interaction with other people. One of the most well known websites for personal interaction is facebook.com, a so-called social network. This service has specialized in communication between individuals on a global scale. It gives its users the opportunity to chat with each other, upload pictures, comment on these pictures, and above all link their self-designed digital representations, the profile, to those of other users. Through these connections, users form a social network in which they can easily interact wherever, whenever and with whomever they want.

In order to achieve this degree of usability, the structure of services offered by the internet needed to change and develop. To become a network of information and people, online content needed to be dynamic instead of static, and content creation needed to be facilitated by multiple users with basic computer skills instead of by specialized web designers. The change from a static medium to a dynamic one was named "Web 2.0" by O'Reilly in 2005 and was described as a system of "applications that harness network effects that get better the more people use them" (O'Reilly, 2006). This statement suggests, first, that websites are no longer simple platforms, which display content, but rather applications, which hold, manage and 
facilitate content. Second, people do not use these applications as a resource only; instead they constantly edit, expand, create, and renew the content found within these applications and therefore extend the capabilities of application constantly. This development from static perception to dynamic participation in online content is what makes Web 2.0 revolutionary.

One key factor of Web 2.0 is that it is not bound to region, ethnicity, culture or language, resulting in a new dimension of possibilities for cultural exchange for people from all-over the world in any language people may want to communicate in. Also, Web 2.0 applications, like weblogs, podcasts, wikis, and social networks are increasingly present in the everyday-life of members of all generations. Prensky (2001) talked about the young generations as being "Digital Natives" (Prensky, 2001), meaning that young people from that generation were "fluent in the language of cyberspace and familiar with the tools of user-generated content" (MacLean \& Elwood, 2009, p. 256), but now, members of all generations are creating social network sites, participating in blogs, and sending Tweets across the world.

Given that Web 2.0 uses technologies with which students are familiar and it makes available easy, authentic cultural communication, it is an ideal tool for meeting the needs of foreign language learners and teachers. Teachers began to 
explore the benefits of Web 2.0 for foreign language instruction and researchers began examining the possibilities made available through these new technologies.

Since the beginning of the $21^{\text {st }}$ century, CALL (computerassisted language learning) research has focused on various implementations of Web 2.0 in foreign language classrooms and has researched its effects on foreign language learning. Many Web 2.0 applications have been found to be beneficial for certain areas of foreign language teaching, for example, weblogs and wikis for collaborative writing curricula.

Researchers have not, however, aligned Web 2.0 with the national standards and used both Web 2.0 and the standards to implement the modes of communication. The standards state that foreign language instruction is facilitated best through the five C's: communication, culture, connections, comparisons, and communities, which together form the framework to which teachers of foreign languages in the United States adhere to.

The benefits for learning languages with Web 2.0 and their link with the Standards for Foreign Language Learning (ACTFL, AATF, AATG, AATI, AATSP, ACL, ACTR, CLASS, \& NCJLT-ATJ, 1998) serve as the foundation of this thesis. I argue that Web 2.0based foreign language teaching is a powerful tool that teachers can use to align their instruction with the National standards in natural and authentic ways. The fourth chapter of the thesis 
provides the reader with concrete examples for implementing Web 2.0 in class and demonstrates how the technologies can be used to incorporate easily all modes of communication (Swender \& Duncan, 1998).

The thesis is divided into four chapters, which are followed by a fifth chapter, the conclusion of the findings and suggestions for future research. Chapter One explains the shift from the static to the dynamic nature of the internet, defines the term Web 2.0 and describes a variety of exemplary application. This chapter introduces the concepts, which need to be understood in order to fully grasp the notion of what Web 2.0 is in both non-educational and pedagogical contexts.

In Chapter Two, I examine the multiple benefits of Web 2.0 for the foreign language classroom in a review of literature. Chapter Two shows the benefits of using Web 2.0 applications in foreign language instruction. Furthermore it examines how students' foreign language learning can improve based on their extended authorship in Web 2.0. I will also examine the positive effects of Web 2.0-based foreign language instruction on student motivation. Finally the effects of using Web 2.0 in the foreign language classroom on cultural learning will be reviewed.

Chapter Three will then relate Web 2.0 technologies to the ACTFL Standards for Foreign Language Education. It will assess how all standards can be met by using Web 2.0 applications as 
tools for foreign language teaching and learning and will give general examples for teaching with Web 2.0 .

Chapter Four relates three Web 2.0 applications, which have not been studied in the research yet, to the modes of communication and the National Standards. After introducing the applications, I will illustrate how all three modes of communication can be addressed by using xtranormal.com, voicethread.com and tinychat.com. These three applications are embedded in a thematic unit for foreign language teaching.

The final chapter will examine the conclusions from the previous chapters and will also give implications for possible future research.

This thesis is designed to provide both a review of research about Web 2.0 in the foreign language classroom and also to provide concrete examples for foreign language instructors to use Web 2.0 for their teaching.

\section{The Advent of Web 2.0}

When O'Reilly (2005) defined the concept of Web 2.0, the perception and use of online interaction seemed revolutionized. The idea of an overhaul of the internet transformed its' concept and "2.0" addressed that it was centered on new ways for users 
to interact online. When looking at the term "Web 2.0" it becomes clear, that there also has to be a "Web 1.0". In this chapter I will describe the developments that led to the distinction between Web 1.0 and Web 2.0. The chapter will explain what the term Web 2.0 means and also focus on the major Web 2.0 applications.

\section{$1.1 \mathrm{Web} 1.0$}

The term "Web 2.0" suggests that this second generation of web interactions must necessarily originate in its predecessor, Web"1.0". To clearly understand the phenomenon of Web 2.0 , then, one must first consider the concept of Web 1.0 . Web 1.0 was first mentioned when O'Reilly defined Web 2.0 in 2005. O'Reilly (2005) speaks of certain applications in Web 1.0 and their counterparts in Web 2.0. This list of counterparts illustrates a shift in the understanding of the Web from a source of static information to a dynamically evolving space for collaborative content creation. The major Web 2.0 applications, which are going to be introduced in this chapter, originated over different timespans. It is therefore impossible to set a concrete point in time for the shift from Web 1.0 to Web 2.0 . 
The various applications associated with Web 2.0 have been developed gradually over the past fifteen years. For example, the online encyclopedia Wikipedia.org, one of the most wellknown Web 2.0 applications, was first introduced in the year 2001. Weblogs, the internet transition between personal websites and "the personal diary and daily opinion column" (O'Reilly, 2005, p. 7), also originated in the 1990s and later evolved to the media we know today as blogs. Rather than describing the advent of Web 2.0 as a point in Internet history when technologies were suddenly changed, the development from Web 1.0 into its millennial counterpart must be described as a diachronic process in which the Internet went from being a static medium to a dynamic platform that depended on the creative abilities of multiple users.

The first change that led from Web 1.0 to Web 2.0 was a technological advancement. In the era of Web 1.0 , content was static. It was created by an author who needed the skills to translate his or her piece of information into HTML (Hyper Text Markup Language). This descriptive code was at the heart of every website, which was then uploaded to a server to make it globally accessible. Unfortunately, in the early days of web production, programs that converted a written text into an HTMLbased website required special training or led to poor-quality results, hence causing content creators to hire professionally 
trained web-designers to publish their work online. This process not only required a great time commitment, it was also expensive.

Web 1.0 is also commonly referred to as the "Read-Web" because users read information rather than produced it. The communication structure between author and reader resembled that of other more traditional media such as newspapers, journals, and advertisements. First, an author created information; this information was then displayed on a website. The reader could access the website and the desired information stored there; however, a direct interaction between the author and the reader never took place. Communication was always facilitated in one direction and did not include feedback. This difference in the interactional model between author and reader is crucial for distinguishing between Web 1.0 and 2.0 .

In addition to the primarily receptive nature of material on the web, the process of creating content for Web 1.0 websites did not invite multiple authors to work collaboratively on a project. Other means of communication were necessary to collaborate outside of the web platform because Web 1.0 was not able to host dynamically editable content that could be accessed by multiple authors. "Whereas Web 1.0 tools allow only website owners (not users) to collaborate or manipulate the information or text displayed, Web 2.0 tools enable users to create, edit, 
manipulate and collaborate online" (Handsfield, Dean, \& Cielocha, 2009, p. 40).

In addition, many internet-users in the late 1990s did not have access to broadband Internet. The low bandwidth resulted in a reduction in quality of the transference of online media. At that time video and audio texts were hardly ever published on the internet. Websites were reduced to pictures and mostly text. The great innovation that would separate websites from books was the introduction of hypermedia (Alessi \& Trollip, 2001), which enabled elements from one medium to connect with other media. These so-called 'links' can be text-elements or pictures and are capable of creating networks of knowledge. Despite the innovativeness of links, the networks they created were static; only the creator of a website could edit it.

In an educational setting these factors made the internet a powerful, but at the same time problematic medium. First, Web 1.0 was not broadly accessible to all students. Whereas today it can be assumed that students have access to a computer that is connected to the internet, this was not the case in the 1990s. The high cost of internet connections and computers made the internet unaffordable for many students and even schools. Computer-labs were available in some schools, but not every student had unlimited access to them. 
In education, the internet served a role similar to that of other, traditional print media. It was used to acquire information or publish information. "However, any exploitation of the web beyond the resource level remained somewhat complicated" (Rüschoff, 2009, p. 45). Web 1.0 had little interpersonal dimension. Chatrooms and e-mail existed, but they were used infrequently and did not provide a useful format for the exchange of pedagogical material. In addition, it was difficult for students and teachers alike to find communicants because the internet did not automatically bring together people of similar interests who would meet in a chatroom at a set time.

Teachers saw the internet as a global stage for the presentation of materials that were created for and in class. When the students were given a task in which they had to create internet content, the students' products were handed in to the teacher who then corrected them. This did not, however, make the internet a significantly different medium from traditional paper-based homework because the students were still creating their products for the teacher, who then submitted them to the greater, authentic audience of the internet. Additional corrections were deemed necessary prior to their publication online because the students' products were to represent the entire school and therefore had to be correct. Because the teacher guided student authors through multiple editing stages, 
they generally viewed the teacher/editor as their audience. While they could rely on the teacher's corrections to improve the quality of the published material, ultimately editing process undermined the true purpose of authentic contentcreation by students.

Another, less teacher-centered use of the internet in class involved having students collect information from the web, which was then put into HTML format. Because programming in HTML was a lengthy process and the teaching of which did not fit into the curricula of most classrooms, the students who had already acquired these skills were the only ones who could transfer the project's content into HTML format. This led to a large amount of extra work that had to be done by a few individuals and that had nothing to do with the core curriculum of the course.

Webquests are a form of learning task Web 1.0 offers, which is still used despide the Web 2.0 transition. Webquests can be defined as "an inquiry-oriented activity in which some or all of the information that learners interact with comes from resources on the internet" (Dodge, 1997). Kurt (2010) further explains that webquests guide a student through different online sources, with the goal of promoting learning by "reading, analysis, and synthesis of web-based information" (Kurt, 2010, p. 178). Webquest sites are typically teacher-generated and lead the students through a sequence of steps. These steps introduce the 
learner to a certain topic by providing online resources as informational material. However, the interactions through a webquest are not truyly dynamic because the tasks of a webquest are not answered online; students answer them on paper. In this case, too, Web 1.0 is merely a source of information rather than a communicative platform.

All in all, the dominant fact about Web 1.0 in the classroom is that it is either used for information gathering or to let students produce islands of information online without user feedback.

\subsection{Turning communication upside down: Web 2.0 and its features}

Now that the status of the internet before the coining of the term "Web 2.0" by O'Reilly (2005) took place is illustrated, the question remains what the striking features of Web 2.0 are, which changed the internet so much that it was considered a second version of itself. Stevens (2006) gives a definition:

“Web 2.0 is a term generally credited to Tim O'Reilly (2005), and refers to web sites and services which are free, where server space is granted in return for signing up for an account on that server, and which are under control of the individuals who add content to the sites" (Stevens, 2006, p.3). 
As we see, "Web 2.0" was made a term in 2005, but its beginning predates the creation of the term. Blogs, for example, were around much longer. Wordpress.com was first published in 2003 .

The first criterion listed by Stevens (2006) is that Web 2.0 applications are free of charge. Also, the person who runs the application itself, is not necessarily an author of information within the application; rather, the administrator provides the necessary web space in which authors interact. In the 1990s it was not possible to do communicate through such a platform, because the necessary technological resources were not available. Server space was rare and data-bandwidth was smaller than today. Now that these resources are at hand, the only thing that is required from the user is a registration process. In fact, greater access to webspace was predictable from the advent of internet technology because the IT (Information Technology) world has, from its inception, been expanding quickly. It was only a matter of time before web space and broadband internet would be available to everyone.

Given the fact that most internet users access Web 2.0 programs free of charge, providers of online applications largely finance their services through advertisements. Over time Web 2.0 applications have demanded a high amount of disk-space and bandwidth and in order to finance the vastly growing need 
for resources to power these application, each online advertisement provides a viable solution for many application providers.

The second criterion that defines Web 2.0 is the open content within its environments. Materials produced by and for Web 2.0 environments is mostly free of copy right laws and is published under the Creative Commons License:

“Creative Commons is a license, under which every producer may publish content online. Every producer can mark text, pictures, design patterns and other media as ' $\mathrm{CC}$ ' and explicitly allows usage to a certain extent." (Panke, 2007, p. 8 )

This lack of copyright laws enhances freedom of writing in Web 2.0. A recent example of ignoring this unwritten law of Web 2.0 is the social network Facebook, which states in its terms of use that every uploaded text, photo or other data is automatically owned by Facebook after publication on the site (Patrick, 2007). Not only is content generally open to public access but also the applications themselves follow the Open Source concept (Stallman, 1999). The concept of Open Source is that software should have its source code published to everyone that wants to edit or elaborate on it. This has the side effect that many Web 2.0 applications are linked together. A user, for example, can dynamically implement posts made to the 
microblogging application Twitter into his or her Wordpress weblog merely by installing a small piece of code or program. These installation processes are well documented and only need a minimum of prior knowledge. Davis (2005) summarizes this openaccess philosophy:

"Web 2.0 is an attitude, not a technology. It's about enabling and encouraging participation through open applications and services. By open I mean technically open with appropriate APIs [Application Programming Interfaces] but also, more importantly, socially open, with rights granted to use the content in new and exciting contexts." The third major attribute of Web 2.0 applications is that their content is user-generated. This means that the content in an application is not made by a Webmaster anymore, but instead by the people that are logged into the website. The front-end back-end technology makes this distinction possible. A user logs into his or her personalized back-end in order to provide content for the website. In blogs, for example, the writers are also seen as users at the same time for which the blog itself serves as a website vehicle to distribute content to their readers. In wikis, this distinction is even more obvious. Every editing site a registered user sees, be it discussion board or actual article, is a personalized backend, through which the user distributes content to the website. 
User-generated content leads to the fourth characteristic of Web 2.0, which is its dynamic, interactive quality. Whereas Web 1.0 is commonly referred to as the "Read-Web", Web 2.0 has been given the title "Read-Write-Web" (Benito-Ruiz, 2009, p. 65). In a medium where every user participates in the creation of content, the distinction between author and reader is obsolete. In Web 2.0 the reader becomes an author and vice versa. Both contribute to the products of the other, edit them and wait for further changes by a third party. "If Web 1.0 is the web of information, then Web 2.0 is the web of communication and participation" (Benito-Ruiz, 2009, p.64). As a result the communicators are often not distinctly called author and producer. Similar to the way in which their roles merge, their labeling also overlaps: They are not "producer" or "consumer" anymore, in Web 2.0 they become a "produser" or "prosumer" (producer and consumer) as for example in Benito Ruiz (2009, p. $63) \cdot$

This merge of author and reader leads to a different use of the internet in communication. Whereas in Web 1.0 the medium was used to convey a message and there was no way for the reader to have a direct effect on the message or the author, in Web 2.0 a content-producing circularity is created in which different produsers contribute to each other's content and hence constantly advance the product. Therefore, the created content 
is not linear anymore, but rather flexible. Nicola Würfel (2008) describes this process as follows:

"Such proceptive environments are characterized (in the ideal case) by their collaborative creation, by which those who participate in the creating process adopt changing roles and that the created artifacts are more and more unfinished but collectively good." (Würfel, 2008, p. 2) Accordingly, content that is developed in Web 2.0 is under constant revision and development. Wikis are a good example of how this process works. Weblogs, too, serve as a good example of collaborative text development. They provide an outlet for amateur and professional authors to write comments about articles published in a weblog. The original author then refers back to a comments made about the original text in the following post, to which responses by readers are again made. This principle of comments can be found in numerous Web 2.0 applications. Downes (2009) describes this phenomenon as follows :

"In a nutshell, what was happening was that the Web was shifting from being a medium, in which information was transmitted and consumed, into being a platform, in which content was created, shared, remixed, repurposed, and passed along." 
The networking aspect of Web 2.0 , its fifth defining characteristic, has not only important technological or communicative dimensions but also an important social dimension, which is commonly referred to as "Social Networking". If a person posts on various blogs or wikis, he or she, over a certain amount of time, creates a social identity, which is a collection of articles he or she has posted. This process is encouraged by personalizing features within Web 2.0 applications in which users may provide a chosen amount of information about themselves. These personalization-features give the user an interface for personal identification with the service they are using. Nearly every Web 2.0 platform is customizable and may be personalized in terms of design and content features. A central element of these customizations are personal profiles, which nearly every Web 2.0 application features in terms of an "about page", which is a site within the application that hosts this personal information. These about pages or personal profiles serve as the identifier of the digital self or social identity. Profile-based interaction within certain applications may also be the center of the social interaction. The so-called "Social Networks" (Facebook, Myspace etc.) have become a center for social interaction in modern communication. These websites let the user create a profile and then interlink it with other people's profiles. The process is encouraged by the option of 
uploading pictures, videos or text and linking these elements to the profiles of other people. A central function in this process is the ability to comment on the media someone posted on a social network. By linking for example a video on Facebook, it may become the central topic of a discussion among the peer group of linked Facebook users. Social Networks also allow communication through text-based chat and the advertisement of artistic projects or items of commercial interest.

The phenomenon of "Social Networking" in Web 2.0 context does not only refer to the social networks but also to the groups of individuals that form a community of interest within one of the Web 2.0 platforms. If, for example, a user posts about a topic on Twitter, anyone can search the platform for the topic in question and will eventually find the former. After such a connection is made, users can directly answer and or refer to posts and form a discourse community. Nicola würfel (2008, p. 4) explains:

"Social-software-applications can be used as informational, communicative, interactional and productive media, while the ability to interact and produce is multiplied, simplified and qualitatively changed through newer applications."

She also writes that the meaning of social networking within Web 2.0 is not only to share information but also to be 
part of a community in which social reputation is enhanced by positive remarks and hit rate (Würfel, 2008, p. 2). This kind of free communication must be critically questioned. Many users of social networks do not often question the publication of private content about themselves and others accordingly. The social network can easily become a launching point for what seems to be an authentic profile of any individual, covering up the user's true character and identity in non-virtual reality.

\subsection{The applications of Web 2.0}

At the time when the name for the new generation of the internet and its uses were collectively dubbed Web 2.0, several websites were already practicing what the term described. They were not individually programmed islands of information anymore, but instead were based on a software pattern, which divided the tool into so-called 'front-ends' and 'back-ends'. A front-end is what the visitor to a website can see. It is the raw surface form, which is filled with information. The back-end is a website that operates separately from the front-end website. The back-end allows those who administer the website, to add content to the website using a WYSIWYG (What You see Is What You Get) editor. These environments resemble commonly known interface- 
structures, such as those of Microsoft Word or Openoffice. Based on the development of front-ends and back-ends, the process of website creation was fundamentally changed. Programming knowledge was no longer required to put information online, which made the process of content creation available to a broad scale of people, instead of just to specialists.

Benito-Ruiz (2009, p.63-64) provides a good overview of the major differences in the following table:

\begin{tabular}{|c|c|}
\hline Web 1.0 & Web 2.0 \\
\hline Web as Read-only & Web as Read-Write \\
\hline $\begin{array}{l}\text { Web as Medium: } \\
\text { Where content is tramsitted } \\
\text { from a webmaster or company to } \\
\text { an audience }\end{array}$ & $\begin{array}{l}\text { Web as Platform: } \\
\text { Where content can be stored, } \\
\text { created, shared, remixed and } \\
\text { commented by each user }\end{array}$ \\
\hline Web of large documents & Web of small pieces of data \\
\hline $\begin{array}{l}\text { Web of Software: } \\
\text { The success of the software } \\
\text { company does not depend } \\
\text { directly on the end-user. If } \\
\text { the user bought and downloaded } \\
\text { the piece of software but } \\
\text { doesn't use it, they still make } \\
\text { a profit. }\end{array}$ & $\begin{array}{l}\text { Web of Content: } \\
\text { If people do not the use the } \\
\text { web-based application (i.e. by } \\
\text { sharing, rating, uploading, } \\
\text { networking), the application } \\
\text { does not exist (nor the company } \\
\text { or startup behind). }\end{array}$ \\
\hline $\begin{array}{l}\text { Web of geeks and techies: } \\
\text { Html knowledge needed }\end{array}$ & $\begin{array}{l}\text { Web of anyone willing to try: } \\
\text { Web-based publishing platforms } \\
\text { (Wordpress, Blogger, } \\
\text { Wikispaces), no need of } \\
\text { technological language }\end{array}$ \\
\hline $\begin{array}{l}\text { Web as Broadcast: } \\
\text { One to many }\end{array}$ & $\begin{array}{l}\text { Web as Conversation: Social } \\
\text { participative nature of web } 2.0 \\
\text { tools, users can share } \\
\text { comments, posts, trackback } \\
\text { other users' comments. Many-to- } \\
\text { many }\end{array}$ \\
\hline $\begin{array}{l}\text { Web as Static: Applications and } \\
\text { Web sites are closed }\end{array}$ & $\begin{array}{l}\text { Web as Dynamic: Applications } \\
\text { are open and remixable via APIs } \\
\text { (Application Programming } \\
\text { Interfaces), recombining and } \\
\text { deconstructing web }\end{array}$ \\
\hline
\end{tabular}




\begin{tabular}{|l|l|}
\hline $\begin{array}{l}\text { Web of Search Engines: You go } \\
\text { to the web to find what's out } \\
\text { there }\end{array}$ & $\begin{array}{l}\text { Web of RSS: Content and data } \\
\text { are subscribable They get to } \\
\text { your computer }\end{array}$ \\
\hline Web of Copyrighted Content & $\begin{array}{l}\text { Web of Copyleft and Commons: } \\
\text { Content can be licensed for re- } \\
\text { use and derivative works }\end{array}$ \\
\hline $\begin{array}{l}\text { Web of Categories: Content } \\
\text { organized and stored in large } \\
\text { and fixed categories by }\end{array}$ & $\begin{array}{l}\text { Web of Tags and Folksonomies: } \\
\text { Smallest units of content } \\
\text { tagged by anyone in the online } \\
\text { community It is the people } \\
\text { organizing web content. }\end{array}$ \\
\hline Web of Forums & $\begin{array}{l}\text { Web of Blogs and Social } \\
\text { Networks }\end{array}$ \\
\hline Web of "Stable" Releases & Web of Beta Releases \\
\hline
\end{tabular}

As stated above, many of the interactive tools for dynamic internet production already existed when O'Reilly (2005) coined the term "Web 2.0". One of them is now one of the primary tools marking the shift from Web 1.0 to Web 2.0: Weblogs, or blogs. In the beginning, blogs were online journals, or logs, as the literal meaning of the term suggests. But blogs soon addressed more and more topics and developed into platforms that present information on any topic that is constantly updated by the author. Because of the front-end-back-end structure, anyone can create and maintain a blog. Several providers, such as www.wordpress.com or www.blogger.com have made the interaction of authors with both known and unknown readers possible through the easy production and manipulation of online blogs. The truly innovative character of blogs has nothing to do with their creation and administration, however. Their revolutionary quality can be attributed to the way in which they 
allow writers to interact with their readers. In a blog, new entries are displayed chronologically. The newest article is always on top. At the bottom of each article, users can leave comments about these articles. This characteristic distinguishes blogs from other, static websites. The commentary structure is a new type of interaction between author and reader and gives the reader the power to communicate directly with the writer.

As more and more blogs were created, the need for dynamic syndication became evident. Many people were blogging on a certain topic and in order to remain current they needed to navigate a mass of bookmarks in their browsers. The technology of the browsers could not, however, stand up to the demands made by this influx of information. Therefore, the RSS (Real Simple Syndication) protocol was created. RSS gathers headlines, pictures, abstracts and complete textual articles from a webapplication and makes this condensed information available for subscription. By subscribing to many different RSS feeds, blog readers and readers of websites that support RSS can keep in touch with a variety of blogs on the same topic. Users can read short teasers on developing stories and can then select which articles they want to read. RSS can also be used by bloggers (people who blog) to interlink blogs with one-another. In this way content from different blogs is dynamically integrated into another blog. 
Additionally, blogs and other Web 2.0 applications, which are subdivided into more than one topic, can be organized by using 'tags'. Tags are labels the author (or in some cases also the user) applies to his or her posts. These tags can then be identified by search-engines that scan Web 2.0 pages for tags and thereby be linked with other, similar pages and posts.

Along with blogs, several other applications use RSS and tags for structuring a broad variety of content on various topics. One of them are Podcasts, which are another Web 2.0 phenomenon that are similar to blogs. The name podcast is a compound word that originated from the words "broadcast" and the Apple Inc. portable MP3 player "iPod". Podcasts are a spokenword or video equivalent to blogs and have the same comment and syndication features. Depending on the software used for podcasting, podcasts even allow users to submit audio-, videoor text-comments through a podcast's website. Podcasts are often published as a series that deal with a particular topic, to which users can subscribe. Users are then automatically notified if a new episode of their podcast is published. Podcasts are, like blogs, syndicated through RSS. Users use a program called "podcatcher" to subscribe to and download different podcasts. Through RSS the program seeks out new episodes of the subscribed podcast series and downloads them automatically to the user's 
computer or mp3 player. Podcasts can also be individually downloaded and are free of copyright restrictions. Originally, podcasts were introduced by Apple Inc. as a new feature of their iPods. They quickly gained in popularity and are now available through many different websites and onlineplatforms. Still the most popular podcatcher remains iTunes by Apple. Another famous example of podcasting is often seen on youtube.com. Youtube is a host for online-videos, which can be formed into a series of video podcasts. These series can be subscribed to just like any other podcast and has a comment function.

Another popular platform, which falls under the category of Web 2.0 applications, are wikis, of which Wikipedia.org is the most well known. This software allows every user to write an article on a certain topic and to interlink words within the article with other articles. This results in a broad collection of interlinked articles. A section for comments accompanies every article on a wiki. In these sections the users of wikis discuss the article and its accuracy. When the users come to a consensus about additions or deletions of parts from the articles, their suggestions are applied to the original article. All changes are traceable, and every article has a complete history of changes made that can be restored to any point of time in its collaborative creative process. 
After a while, a collection of articles on a wiki can reach enormous dimensions and can, like wikipedia.org, become a whole encyclopedia. Wikipedia.org, at the moment, is the largest encyclopedia in the world. It is also available in many different languages. Its goal is to make the knowledge of humankind available to everyone for free.

Evolving from the concept of blogs, twitter.com is one of the more recent additions to Web 2.0's primary programs. It allows people to conduct a 'micro-blog', which is a blog that consists of messages that have a restricted text-length. Launched in July 2006, Twitter.com has had a great impact on people's interaction through media. Although the microbloging service only allows messages of 140 letters, Twitter messages, or "tweets", are the vehicle for countless updates on global or private occurrences from around the world every day. Twitter.com defines itself as follows: "Twitter is a real-time information network powered by people all around the world that lets you share and discover what's happening now" (Twitter, 2010). Institutions or private persons alike can publish the information present on Twitter. Twitter pages are organized like blogs. They are a continuous feed of messages found on the sites to which a user has subscribed. Twitter users can interact by replying to each other or sending direct messages. Twitter messages can also contain tags, which are marked by a pound 
sign. These tags allow users to search for all tweets on Twitter dealing with the same topic.

Overall, blogs, podcasts, wikis, and twitter are only a few examples of Web 2.0 applications, but they are among the most popular and important. Their features comprise a list of characteristics generally attributed to the term Web 2.0.

In conclusion, Web 2.0 has revolutionized the way people interact online and the way people use content online. Because these two factors both involve communication, they need to be facilitated through some type of language. This leads to the assumption that Web 2.0 , if used effectively in foreign language instruction, might have positive effects on the way people learn languages. Chapter two will illustrate these uses and effects of Web 2.0 programs in foreign language instruction and its effect on learner motivation and acquisition of the language.

\section{Web 2.0 in language teaching}

The shift in usage of the Internet among casual online users has not only changed their perception of online media; it has also caused a similar shift in the perception of web-based computer assisted language learning (CALL) in current foreign language pedagogy research. Factors like the widely spread 
availability of broadband internet access and the growing integration of online platforms into everyday communication have increasingly drawn the attention of educators and researchers to the pedagogical benefits of using Web 2.0 in classroom teaching. Not only do Web 2.0 applications increase the interest level of learners in class, but it also encourages them to continue their learning beyond the classroom using technologies with which they can work at home.

Research on the use of Web 2.0 in the foreign language classroom has been the focus of CALL research throughout the last decade. This chapter will review important contributions to the research and illustrate that four themes emerge regarding the types of research dedicated to Web 2.0 in the foreign language classroom. They include:

1. The history of Computer-Assisted Language Learning and its Relation to Web 2.0 ;

2. Web 2.0 applications in the teaching of language skills;

3. Motivating factors of Web 2.0 in the classroom; 4. Web 2.0 as a tool for cultural learning.

In the ensuing discussion, I will examine previous and current Web 2.0 research and the various advantages and disadvantages of using Web 2.0 in foreign language teaching. 


\subsection{The History of Computer-Assisted Language Learning and its relation to Web 2.0}

As Web 1.0 technologies developed into to Web 2.0 , the use of online resources in the foreign language classroom has shifted as well. Before examining specifically the effects of Web 2.0 technologies on foreign language pedagogy, it is necessary to examine the transformation of Web 1.0 to Web 2.0 . Trotman (2000) introduces a historical overview of internet usage. In the early 1990s many educators did not yet implement web technologies in their teaching because of the ever changing nature of the web and the pedagogical and technological opportunities it afforded. Trotman (2000) divides the evolution of CALL into three stages. The creation of "small, copyable grammar activities or text reconstruction programs" (Trotman, 2000 ) marks the first stage of computer technologies in instruction. This stage of CALL, implemented in the 1980s, was marked by the limits of early technological advancements. Computers did not yet have the capacities to play video or audio files; they were used for text-display only and could calculate basic routines based on a textual input-output schema in which a user fed text to the machine. This text was then analyzed or 
transformed into another piece of text by the computer, which then displayed the results of its calculations on the screen. The second stage of CALL instruction, according to Trotman (2000), features multimedia tools, namely the CD-ROM of the 1990s. This new data medium could store large amounts of data, such as pictures and video, and gave a new interactive dimension to computer-assisted language learning. It was possible to record authentic language examples and deliver them to learners not only in text, but also through a multi-media environment. The third stage that Trotman (2000) describes was characterized by the emergence of the internet. The internet was a unique and revolutionary tool in the foreign language classroom because it provided language learners the ability to communicate with their instructors, their peers, or native speakers outside of the classroom in a fast and uncomplicated way •

During the 1990s the possibilities of computer-mediated communication (CMC) were extensively explored and researched. Warschauer's (1997) article introduces five features of the internet and their potential use in foreign language teaching. The first feature, text-based and computer-mediated interaction, offers learners the opportunity to interact with other foreign language learners directly, and students are encouraged to reflect and interact, for example, by using E-Mails or 
chatrooms. They can also review their communicative history and reflect on previous interactions. This provides learners with the ability to analyze their communication, find errors, or to simplify the structure of their arguments better by looking at what was said before. In SCMC (synchronous computer mediated communication) reflection is amplified by chatroom technologies, in which the textual history of the conversation is always visible. Warschauer (1997) mentions Kroonenberg's (1994/1995) study, which exmines how synchronous CMC increases the quality of arguments in a follow-up discussion through the reflective features of SCMC.

The second innovation Warschauer (1997) discusses is manyto-many CMC. "CMC creates the opportunity for a group of people to construct knowledge together, thus linking reflection and interaction" (Warschauer 1997, p. 473). He also explains that the dynamics of online communication are different compared to face-to-face interaction in terms of "turn-taking, interruption, balance, equality, consensus, and decision making" (Warschauer 1997, p. 473). Turn-taking, in most CMC environments, is a given factor. In both, E-Mail and text-chat, the communicating parties take turns when speaking. This is not a given factor in face-toface communication. Here several people can talk at the same time, making it hard to follow the communicative process. The only SCMC mode in which this would be possible is voice- or 
video-chat. The process of turn-taking makes CMC free of interruptions and provides conversations with a high level of structure. In addition, CMC eliminates social factors in conversations, such as prejudices between speakers, because of its anonymity. Finally, a consensus can be reached more easily because the whole conversation has a clearly detailed structure. Furthermore Warschauer (1977) states that CMC lowers the learner's anxiety with regard to participation in in-group discussions by reducing social context barriers and non-verbal communication-elements. By lowering the affective filters (Krashen, 1982), learners are more likely to take risks with language production and thereby increase their languagelearning. According to Weisband (1992), it took students much longer to agree to a statement than in a face-to-face discussion.

Despite the positive aspects of CMC in foreign language instruction, Warschauer also identifies shortcomings of the technology. According to Warschauer (1997), the anonymity of a CMC environment leads to inappropriate language use by the learners; students are more likely to monologue and they are distracted by the need to respond both to the teacher and other students.

Warschauer's (1997) review of literature gives a good overview of how students could benefit from pre-Web 2.0 
internet-based foreign language instruction, and his findings are just as valid for Web 2.0-based instruction. Still today, online communication is in many cases text-based, blogs and wikis are only two very prominent examples. Warschauer's analysis of turn-taking, consensus, and especially the effect of technologies on the affective filter are still valid today because Web 2.0 has not moved away from text-based communication. The innovative development of the internet and its uses in foreign language teaching that Warschauer (1997) depicts not only paved the way for new instructional methods but they also serve as the foundation of Web 2.0 instruction, which marks the next wave of innovation in foreign language instruction.

Next, Sturm, Kennell, McBride and Kelly (2009) link learning in Web 2.0 closely to social constructivist approaches to language learning. This approach has been deemed one of the fundamental aspects of classroom interactions among foreign language learners. They claim that social networking and collaborative learning environments, which are features of Web 2.0, foster learning through a structure in which learners get input from outside sources and then reconstruct their own knowledge. They "actively use new material rather than passively absorb information presented to them" (Sturm et al., 2009, p. 371). Based on the active role of the student in acquiring new 
knowledge, Web 2.0 is a natural platform for teaching foreign languages because students take new information and form a product, like a blog, podcast or wiki page, from that new knowledge. The authors state that in the social constructivist approach to learning, the teacher has a subordinate role, and the learning environment is student-centered. Teachers "are generally regarded as facilitators guiding learners through their interaction with the learning material and supporting the collaboration with other learners" (Sturm et al., 2009, p. 373). When the teacher takes on a facilitator role, the students must take charge of their own learning and steer the interactional process from which language practice and communication ensue. Furthermore, Sturm et al. (2009) state that Web 2.0 technology is especially useful for teaching students to think critically, reflect on their work and discuss their findings. They use blogs and wikis to illustrate these criteria "because their content is part of a wider body of knowledge accessible and potentially relevant to an audience outside the classroom" (Sturm et al., 2009, p. 378). Students' participation in blogs ultimately leads them to reflect more on their language use, because students have an authentic audience and see a greater purpose for their work.

Benito-Ruiz (2009) introduces a negative aspect of Web 2.0 technologies and the many opportunities it affords. She argues 
that the mass of information on Web 2.0 presents students with overflow of information that is not easily processed. She claims that this can be avoided when learners use real simple syndication (RSS) to categorize sources of information on Web 2.0 and pick only the topics relevant to them. Almost every source on Web 2.0 can be subscribed to by an RSS feed reader, which shows the headline and a preview of the contents of a Web 2.0 site. Benito-Ruiz concludes that the creation of RSS categories provides relief to users because it allows them to reduce the amount of information through which they must sift. If users do not reduce the amount of information they are receiving, they become overwhelmed with material and are less likely to be interested in using the medium.

According to Benito-Ruiz (2009), it is impossible for students to take in every piece of new information offered through Web 2.0; students or teachers must select input carefully in order to avoid getting lost in the amount of information that is available online. Thus, it is the role of the facilitator, the teacher, to teach students to use Web 2.0 resources appropriately, and to filter out effectively sources that are of low relevance to the students' work. If students learn to work through this process, however, Web 2.0 remains a great source of authentic communication and information. 


\subsection{Web 2.0 applications in the teaching of language skills}

While it is clear that the World Wide Web offers a vast amount of information that is both authentic and motivating to students, the amount of information available for consumption must be restricted and approached in a well-structured manner. In this section we shall look at web-based interactions that allow the teacher to establish a framework for web usage and thereby help students make the most of the medium in their language learning.

One of the most important forms of Web 2.0 programs in the foreign language classroom is the wiki, because of its promotion of collaborative written work. The study by Elola and Oskoz (2010) focuses on the difference between collaborative writing in a wiki and individual writing and highlights how the wiki platform encourages collaboration. The authors also investigate the element within the writing process on which the students focus while writing in a wiki, both as individuals and in a collaborative setting. Finally, they examine students' perceptions on the difference between individual and collaborative wiki work. A self-evaluation by the students of their performance while working with the wiki serves as the final aspect of the study. 
The participants in Elola and Oskoz' (2010) study consisted of eight students of Spanish as who were enrolled in a distancelearning course at a commuter university in the United States. The students completed a first writing assignment collaboratively in a wiki environment during the first two weeks and an individual assignment during the second two weeks. They had multiple opportunities to plan and review their writing. They also completed two surveys in a pre- and post-test manner. The researchers discovered that while working collaboratively, students focused more on organizing and editing and less on structure; while working individually, students focused on content and organization to some degree, but they devoted more time to grammatical accuracy and the structure of their writing. Interestingly, however, they focused less on editing and vocabulary. Students also used chats to talk about their wiki articles, in which they mainly discussed the content of the texts they were writing in order to come to an agreement on which content to present.

As a result of the pre- and post-survey, the researchers found that the students felt that wikis helped them less with grammatical structures than they had expected. During the posttest, half of the students stated that writing in a wiki helped them address weaknesses in grammar and improve them. Students stated that wikis were helpful to them in developing content and 
structure. Students felt more comfortable when approaching the wiki-based writing task individually than in a group because they felt that "they retain more control over their writing, they establish their own personal style, and they are not dependent on the input of others" (Elola, \& Oskoz, 2010, p. 64). Elola and Oskoz underscore an additional difference between collaborative and individual writing in a wiki involving the sequencing of turns among writers. During the individual writing phase students polished their grammar while writing, generated ideas during a final review phase, and worked on structural matters throughout the entire process. During the collaboration phase they generated ideas before the writing process began and established the structure at the beginning. This finding is interesting because students seem to invest more time in the planning process when engaging in collaborative writing than when they write on their own. This has a positive effect on the writing process because while writing collaboratively, students present an idea to others and elaborate on it, rather than creating the planning stages collaboratively. They seem to value collaboration more for enhancement of their ideas than for planning their writing.

The limitations of this study are that the sequencing of the two phases may have skewed the results because their behavior in the wikis could have influenced their individual 
writing. It would be compelling to do a similar study which involved having the students write individually first and collaborate afterwards to see if students would invest more time in the planning phase if they had done the individual writing first. It would be interesting to see if the individual work would have different effects on the collaborative phase, if it preceded the collaborative phase.

Overall, this study is compelling because it considers distant learners who do not have the means to communicate in face-to-face interaction while working on the wikis. This lack of face-to-face contact increases the amount of communication that is necessary to collaboratively create a written product. It would be interesting to see this study conducted again with more participants and a series of tasks in order to find out if the results are still reliable in a broader setting.

A second study that examines the effects of collaborative writing in a Web 2.0 format was conducted by Kessler (2009). The author researches the degree to which EFL students correct their own grammar and that of a peer during a collaborative writing task and the degree of accuracy the students actually achieve through this process.

The participants in this study were 40 Mexican EFL students of similar language and technology proficiency. They were given a writing-task in a wiki environment and carried it out 
completely autonomously. The teacher did not intervene during the process, thereby making the students responsible for construction of text. Their teacher in class reminded them of the wiki-project every four weeks throughout the semester. Their contributions were rated at the end of the course, and errors were isolated and categorized. Twenty of the students took part in follow-up interviews.

Kessler found that students peer-edited each other and were not afraid to criticize. Like Elola and Oskoz (2010), researchers found that in a wiki environment students were not reluctant to criticize; this feature of wikis is strongly supported by research.

One interesting aspect of the findings is that students did not focus too much on form because they saw the wiki as an informal setting that did not require special attention to grammatical correctness. The students were not willing to make the product grammatically perfect. They "expressed surprise that there would be any focus on grammar" (Kesseler, 2009, p. 90). This result shows that students feel less formal in a wiki environment when the teacher is not involved in the contentcreation process. The students alone felt less obligated to polish the grammatical accuracy of their writing.

It is likely that the degree of autonomy that the students experienced in this task made their working environment appear 
informal to them. This would explain the lack of attention to grammatical accuracy and overall grammatical improvement. Another important Web 2.0 technology that has been implemented frequently in the foreign language classroom is the weblog. Campbell (2003) divides blogs into three subcategories: the tutor blog, the learner blog, and the class blog. Campbell describes these subcategories and demonstrates how learners can engage in blogging activities to facilitate their linguistic development.

The tutor blog is a blog that is made solely for organizational purposes and for giving students a source of information. In a tutor blog the teacher is at the center of the blogging activities and can provide an overview over classcontent, a calendar with class-related events such as the dates of quizzes or exams, and content material, which would normally be handed out in class. This is especially useful if a student missed a class; the student can go to the tutor blog and review all the material he or she has missed. This is also valuable for homework assignments. Through the use of a tutor blog, teachers can always ensure that their students are up-to-date and informed about the material covered in class. Students may leave comments or ask further questions to the teacher, but an interaction between users, while possible, is not the primary goal of the tutor blog. 
The learner blog is created by students for interaction with their peers. Students post an article and get feedback from other students in the class. Students reflect on their own and others' learning and are provided with the opportunity to extend their discourse community beyond the boundaries of the classroom and involve other people to comment and interact in their blogs. For this to happen, the blog has to be made searchable by blog search engines. After creating the blog and its content, and having it reviewed by peers, a student can open the blog to the public and receive authentic content from people outside of the classroom to whom the topic of the blog is meaningful. By doing so students see the relevance of their work, which reaches far beyond the walls of the classroom.

According to Campbell (2003), class blog describes the situation in which a whole class works on one blog. The main difference between the class blog and the learner blog is that not all students have their own blogs; instead the class blog is the product of a collaborative student-writing process.

A study that researches the effects of blogging in learnerblog environments is an action-research project by Ducate (2008). The author examines the different steps students go through while working on a blog project. The author considers the process of reading and writing in blogs, student's reactions 
towards blogging, and looks at how self-expression is characterized in weblogs.

The study was conducted over two semesters. During this time the number of participants changed between the semesters. In the first semester 20 third-semester students of German and nine fourth-semester students of French followed blogs that were written by a native speaker. Their task was to give a formal class presentation about the bloggers' culture at the end of the semester. In the second semester, ten fourth-semester students of German and eleven fifth-semester students of French wrote and maintained their own blogs in the foreign language, and their classmates commented on their posts. The researcher collected data in questionnaires prior to and after the semester. The researcher found that during the first semester students went through several stages while working on their blogs. They first chose a blog and then, after a certain amount of time, read the posts on the blog to familiarize themselves with the blogger's language and style. They then identified similarities between their own culture and the culture of the blogger. Based on this information they tested and eliminated prejudices about the foreign culture. All students compared their bloggers to themselves during the presentations.

In the second semester, the students established their own blogs and then posted about topics from the class and other 
topics of personal interest. Students also received responses from native speakers via the comment function of their blogs and engaged in conversations with these speakers in the target language.

The researcher found that students followed the suggested task-sequence in order to find out about the target culture. The students did so by first identifying and engaging with the blogger they followed, which functioned as an authentic cultural role model for them and with whom they communicated through the commentary function of the writer's blog. The researcher states, however, that the students' insight into the target culture was limited by the views and impressions the respective native speaker provided for them. The researchers' final questionnaire revealed that students felt that their reading and writing skills had improved. They also stated that they had learned new material through their blog-interaction with other students in the class.

Future research is necessary to substantiate the findings of this study because the cultural images and opinions mediated to the students from the target culture would likely be significantly different if the students followed a group of bloggers from the target culture rather than just one. After the two years students underscored that reading blogs was enjoyable and they felt their cultural knowledge had increased. 
It would be interesting to know, whether the participants from the second year were part of the study in the first year. If that information were available, the cultural learning process would be more traceable to the combination of both years of cultural learning, rather than only one of them and, if there were dropouts, provide an analysis of their perceptions of the task. This would let the reader know, if a one-year instruction that is modeled after this article's treatment, could lead to beneficial results for students.

Whereas the previous two articles focused more on how students use blogs in the classroom, the study by Xie, Ke, and Sharma (2010) focuses more on how the students use the blog itself and how differences in a blogging task-type can influence the student's learning experience. They investigated different types of questions in a blog post that introduced a topic and used it for starting a discussion. The researchers investigated in what ways this initial post affected the learners' arguments within the discussion and the students' final textual products within the blog. The two starter styles within the initial post were formulating the starting post in a blog as a question or as a monologic statement. The researchers asked whether the “[...]different starter styles (questioning vs. monologuing) affect the quality of student starter posts in terms of deep cognitive thinking, as exhibited by these posts and the length 
of the starter posts [...]" (Xie et al., 2010, p. 463). Researchers also examined how starter styles affect comments, and they looked to see, whether being a starter or commenter had an influence on the nature or number of meaningful units in the posts. Finally, they looked to see if the participants' level of thinking as starters predicted the level of their thinking as commenters.

The sample group of the study consisted of 34 undergraduate students aged 18 to 30 who were enrolled in two sections of an introductory ESL course. The class met three hours a week and had weekly blogging assignments. The students were grouped into groups of five. One student in each group started a conversation in a blog and was asked to use one of the different starter styles. The instructors of the class evaluated the student's posts over the course of a thematic unit.

The researchers found that monologuing produced longer starter posts and more high-level thinking processes than the question starter. Researchers also found that the replies to all starter styles had the same length, but the questioning style elicited higher level thinking in the reply posts. Students who started a post produced more meaningful units; however, no significant difference in higher-level critical thinking was evident. Only a low percentage of students contributed to discussions focusing on high-level topics. Researchers found 
that the participants' level of performance inverted after they exchanged starter/commenter roles. Finally, the researchers conclude that the monologuing starter style causes the students to see blogging as journaling from an introspective point of view. Students see themselves in the center of the taskanswering process rather than incorporating others or even collaborating. Questioning as a starter style, on the other hand, makes the students perceive the blogging task as interactive and collaborative.

In addition to more traditional forms of blogging that are mainly text-based, audioblogs, which follow the same concept of blogging but are audio-based, have also grown in popularity. Hsu, Wang, and Comac (2008) examine these audioblogs and their use in foreign language instruction. In particular, they examine how the implementation of audioblogs in class can improve the quality of instruction and ultimately the oral performance of students. The authors ask how an audioblog can complement instruction and how students perceive improvement in their oral skills.

The participants of the research study were 22 international students in an advanced English conversation class. The students recorded audioblogs with their cellphones and uploaded them to a blogging platform. The teacher commented on the blog and gave the students individualized feedback. The 
teachers gave feedback within the blog but it is not reported whether they recorded a message or gave textual feedback. Because the tasks were mostly for the improvement of pronunciation teaching, however, a recording was likely necessary. The researchers conducted a survey that examined the attitude of students towards the data-collection procedures of the study and the use of the audioblog as a learning tool. Students also answered open-ended questions about the project, participated in an interview with the instructor, and responded to the student audioblog posts. All of the 442 student audioblog recordings were considered for the data.

The researchers found that students faced few difficulties when interacting in the audioblog environment. This can be attributed to the fact that they are used to making voice recordings using their cell phones. Students saw audioblogs as a rich platform for foreign language learning and agreed that individualized feedback helped their learning because they received it on a regular basis. The use of cell-phones as recording tool supported the students' positive attitude towards the authenticity of their speech because they were encouraged to speak naturally in their recordings. In the open-ended questions in the survey, students suggested that a comment function be included in order to foster collaborative interaction among 
participants. According to the students, this would have led to a deeper engagement with the topic.

Students also stated that the method was time-efficient. The instructor, however, expressed the contrary view of the audioblog activities, explaining that with a growing class size, time would be an issue that would challenge the quality of the teaching method. Overall, this is a common problem with individual feedback in any setting: The bigger the class size, the more problems the instructor has finding the time to give quality feedback. A possible solution to this problem would be a team-teach setting, in which a group of learners with audioblogs work with multiple instructors so that each student gets indepth feedback.

Hsu et al. (2008) concluded that the task needed more multimedia input and more task variety. Students stated that it would be good to incorporate videos and a variety of authentic media into the task samples. The researchers further claimed the need for a holistic rubric to assess the students' performance. The scholars agreed on the necessity of a smaller class size, which had already been suggested by the students.

It would be interesting to know if the students carried their positive learning experience beyond the classroom boundaries and if they looked for native audioblogs authors on their own. 
The research so far has shown that students' foreign language learning can benefit from Web 2.0 applications in various ways. Elola and Oskoz (2010) showed, that wikis can help students with the content and structure of their writing. Also, their students felt more comfortable, which improved their overall results in the collaborative writing task. Kessler (2009) found that students peer-edit one another and that they are not afraid to criticize in a Web 2.0 environment. However, the students in this study saw the Web 2.0 environment as an informal setting, which leads to the conclusion that they saw it as separate from the usual instructional setting. Ducate (2008) also found that students reading and writing skills improved and that the students found their tasks enjoyable. The students also stated that they felt their cultural knowledge increase. Furthermore, Xie et al. (2010) found that students would give different quality responses when they were introduced to a blog post differently. Hsu's (2008) students stated, that individualized feedback would be highly appreciated by the learners and that they valued the commentary function in Web 2.0 applications. These student responses lead to the assumption that if students are pointing out all these positive effects in different studies, there might be an effect of Web 2.0 applications on the motivation of foreign language learners. 


\subsection{Motivating Factors of Web 2.0 in the Classroom}

Upon the examination of Web 2.0 in foreign language instruction and its effect on student learning, one specific feature stands out: the importance of technology on improving student motivation. Motivation has been extensively researched in various ways and "it makes sense that individuals who are motivated will learn another language faster and to a greater degree" (Gass \& Selinker, 2008, p. 551). Gass and Selinker (2008) define the term motivation in accordance with Gardner (1985) as consisting of four parts: "a goal, effortful behavior, a desire to attain the goal and favorable attitudes toward the activity in question" (Gass \& Selinker, 2008, p. 511). The combination of these four elements motivates students to learn the language and therefore, leads to better results in student performance.

According to Gardner (1985), there are two types of motivation: integrative or instrumental (Gass \& Selinker, 2008). If a students' motivation is of an integrative nature, they are interested in learning the language in order to become a part of the target culture. Instrumental motivation, by contrast, describes the student's primary reason for learning as a response to the need for fulfilling a requirement that is imposed upon him or her (Gass \& Selinker, 2008). 
In order to discover to what degree Web 2.0 technologies have a positive effect on student learning, a number of studies have been conducted to analyze the relationship between motivation, participation, and performance in activities.

The research of Wang, Wang, Fang, and Lin (2010) provides insights into the influence of Web 2.0 on student motivation through the examination of the technologies' effects on learning outcomes in a foreign language college writing curriculum. The focus of the research was to determine the impact of Web 2.0 use on foreign language learning and teaching and to examine the benefits of Web $2.0^{\prime} \mathrm{s}$ use for both learners and teachers.

The participants of this study were 55 Taiwanese students who were introduced to the concept of blogs and online work in order to make sure that they all shared the same basic knowledge. The group met weekly and was assigned a collaborative writing task. The group was then divided into two smaller groups, one of which used blogs to facilitate this writing task while the other used face-to-face communication. The blog group read the postings of their fellow bloggers while the face-toface group discussed their findings in the classroom. Finally, the researchers collected data from forty-five questionnaires. The researchers found out that one great benefit of the blogging group was that blogging was space-independent and that blogs had a positive impact on students' motivation. Students 
felt involved and, therefore, more connected to the task. "A majority of the respondents (79.0\%) truly believed that their efforts benefited their group towards the group project" (Wang et al., 2010, p. 446). They were especially motivated by weblogs because they provided learners with a new way of interacting in an authentic setting. Students also stated that blogging made them aware of the insights of their peers and they were, therefore, more likely to learn from them.

An important conclusion the researchers came to based on their findings is that the role of the teacher changed when using Web 2.0 technologies. In this platform, the teacher no longer serves the role as the provider of knowledge but acts instead, as a guide in the students' search for knowledge. Because students are responsible for seeking out knowledge on their own, they are more likely to explore and less likely to depend on their teacher alone to provide them with information. In addition, students are motivated by the fact that they are part of a bigger project and can see the progress of the group at any given time on the blog platform.

This study does, however, leave some open questions. First, the participants are not well described. It would be helpful to know where the students come from and if other participantrelated factors influenced the research. It would have been interesting to know the students' proficiency levels at the 
start of the project, and how much contact they had with weblogs in the past. It is also unclear why only 45 questionnaires were collected and analyzed when there were 55 participants in the study •

A second study that investigates effects of Web 2.0-based foreign language teaching on learner motivation is the study by Pop (2009). The purpose of the study was to show that Web 2.0based English for Specific Purpose learning is superior to classical instruction in terms of learner satisfaction and motivation.

The participants of the study were 122 second-year students of Economic Sciences from Romania in two different ESP classes, which were both taught by the same teacher. One class, which consisted of 70 students, functioned as the control group and was taught with traditional methods. The other class, the experimental group, consisted of students who were assigned the same tasks as the control group but used blogs, wikis, and other Web 2.0 tools in the learning process and received their instructions through these platforms. The level of satisfaction the students experienced with regard to their own learning was measured by a survey. They analyzed student satisfaction in terms of their satisfaction with and interest in the platforms, and to what degree these factors influenced students' completion of course activities. The research also examined students' 
interest in attractive presentation and the degree to which students felt stimulated and motivated by the Web 2.0 materials. The students' motivation was assessed by a questionnaire that consisted of Likert-scale items, which included students' perception on the structures in which the tasks were presented and a self-evaluation of their own motivation during the tasks. The researchers asked the student to evaluate their gratification, which was sent to lead to a higher degree of motivation. Motivation was also measured by the degree of student involvement.

Pop (2009) found that the students from the experimental group perceived the material they received through Web 2.0 applications as very structured and attractively presented. The control group was neutral toward the traditional presentation of material they received in the form of printed prompts and traditional test questions. The researchers concluded that the presentation within Web 2.0 applications was more authentic and, therefore, more motivating for the students. The author also reports from the surveys that writing for an authentic audience was motivating for the students. This motivation was related to different modes of presentation that the materials were presented to by the students. Also, students produced much more accurate language than their traditionally instructed counterparts. The students ability to contribute in a non- 
synchronous communication Web 2.0 environment also encouraged students to participate more. Finally, students felt motivated by the fact that they were writing for a real audience, rather than just for the teacher.

It must also be mentioned that this study had some limitations. On the one hand, the study involved a large number of participants who were described in detail. On the other hand, the methodology was described vaguely, and the questionnaire seems to only consist of two items. It would be interesting to see more findings from this study, such as more detailed analysis of factors that motivated the students. These findings could then, in a future study, be compared similar Web 2.0 applications in order to come up with a generalized rule about why and in what situations Web 2.0 applications are motivating. Finally, a stud by Alm (2006) considers the relationship between Web 2.0 and learner motivation. Alm refers to the behaviorist model of stimulus, feedback, and response used in early CALL instruction and for the development of lower-level thinking skills, e.g., vocabulary trainers. In this model, the computer program itself motivates the learner (Alm, 2006), in contrast to a model of self-determination, in which an outer motivation is not necessary and the learner's inner desire to discover serves as the impetus to learning. In Alm's (2006) model the learners' inner desire to discover situations 
motivates them and a stimulus is unnecessary. Alm (2006) argues that this part of motivation can be achieved through "psychological needs of competence, relatedness, and autonomy" (Alm, 2006, p. 31). In terms of relatedness, Alm (2006) states that Web 2.0 tools are especially fruitful for motivation because through social networking students can relate to each other instead of the teacher only in the traditional classroom or the computer itself in pre-Web 2.0 CALL. The author also points out that in order to maximize learners' motivation, it is important not to overwhelm them with the difficulty of the task. In this regard, Web 2.0 can be structured for finding content that is appropriate to the learners' level. At the same time, the influx of information can serve to limit the development of learner competence by either giving too much information or the wrong kinds of information.

A final component of motivation, according to Alm (2006), which inspires students to participate in autonomous learning, is the role of relevance. Students are more likely to undertake a task and see it through to its conclusion if they see the relevance of what they are doing. Based on the public and reallife nature of Web 2.0 content, students see a real-life application of what they are learning and are, therefore, able to relate better to the learning tasks. 
After reviewing these articles, it seems evident that Web 2.0 applications have a motivating effect on students. Wang et al. (2010) found that blogs have a positive impact on students' motivation. Students feel involved and connected to the task, which gives them favorable attitudes toward the activity and the goal of connecting with the task itself. Pop (2009) explains that the presentation of information is perceived as authentic by students and, therefore, leads to an increase in student motivation. Finally, Alm (2009) states that students are motivated by curiosity and want to explore their new knowledge. Alm (2009), in accordance with Benito Ruiz (2009), states that students must not be overwhelmed with input and that controlling the amount of input is an important factor on students' level of motivation.

Another important factor that increases students' integrative motivation is the audience within the Web 2.0 discourse community for which the students write. Because the motivating factor of Web 2.0 is its use of authentic interactions and real-life situations, it is important to examine the audience with which the learner is interacting and how these interactions affect the learners' acquisition of the language. Raith (2006) provides insight into this topic in a study that investigates the influence of the online audience in 
the writing process. In this study the notion of audience refers to the students who post comments on their peers' blogs. The participants of the study were 29 students from a ninth-grade class at a Realschule, which is part of the German middle- and high-school system, in Heidelberg, Germany. The students were given the choice whether they wanted to work on paper-based projects or weblogs. Ten students chose to work on the blogs. Their decision was based on former experience with blogs and their personal comfort with technology. The students had to go through various steps of a literature project. Students from the paper-based group had to write down their thoughts and feelings about a piece of literature. Students from the blog group were given an introduction to weblogs and then received the same task in an online format. In addition to completing their own writing tasks, the blog group was asked to post comments on their peers' blogs. The data from a questionnaire and an interview after the first questionnaire were used to gather information about this study.

Raith (2006) found that the texts from the weblogs were of higher quality than the paper-based group. Students revealed more personal interaction with the text; they did not just summarize it. Also, the students who typically exhibited weaker performance in the class generally chose the paper-based format. Students in the middle of the performance spectrum that chose 
blogs, however, performed better than their counterparts who chose paper-based tasks. Students that wrote in the weblogs possessed an awareness that they were writing for a community, one possibly even outside of the classroom. This awareness ultimately appeared to influence the quality of their writing. Students stated that blogging gave them a means to interact with the target-language audience that was low-anxiety and easily accessible. By contrast, among the paper-based writers, the audience was named a notable factor only by a quarter of the participants. Many bloggers even stated that their interaction had positive effect on their writing.

A second study that focuses on the influence of the audience on students' performance is the case study by Kuteeva (2011). This article investigated the reader-orientation of writers in a wiki. It furthermore examined among students writing the wiki, the effect of the wiki on structural organization and grammatical correctness and the degree to which the resources of meta-discourse in a wiki are used.

Fourteen students from different study backgrounds and between the ages of 20 and 54 served as participants in this study. The students were assigned to write texts in their respective academic contexts. They first had to write headlines and then elaborate on them, after which the texts were merged together. Then students had to write an argumentative essay on 
the wiki. For this task all students received their own section within the wiki where they read and discussed each other's essays. The researcher observed the participants, analyzed their texts on a grammatical basis, and had the students fill out self-report questionnaires.

The author found that the students did not feel urged to use formal vocabulary on the wiki. The lack of attention to formality might originate from their use of wikis in their every-day life; they do not associate the form specifically with a scholarly audience. Experts in the field also often deem Wikipedia, which is the most famous wiki site, unscholarly. Therefore, students might get the impression that wikis are informal and not always tested for accuracy. Though the students checked their writing for grammar and spelling, the texts displayed a minimal number of mistakes. The students stated that they wrote reader-oriented texts because they had thought of their correcting peers as readers. In the first collaboration assignment, the students focused on guiding readers through the text rather than inviting them to collaborate. The essay assignments, on the other hand, demonstrated a high frequency of engagement markers, such as personal pronouns. This study featured a rich description of participants, procedures and results. It gives interesting and detailed insight into the process of peer correction and collaboration in a wiki 
environment. The fact that students may perceive the audience as informal, if their goal is to write for their peers as an audience. It might be interesting to repeat this study with specific instructions to write for a more formal audience at the end and then compare the results.

These articles have shown that the audience, which is directly involved in the communication process when working with Web 2.0 in a foreign language class, plays a central role in the way students perceive the task and engage with it. Students develop a more personal relation to their texts and are aware of the fact that they are writing for a community, which serves as a source of integrative motivation. While students do not use formal vocabulary, they make only a minimal number of mistakes and they are more aware of their audience during the writing process. They are more likely to invite their peers to collaborate, and they are less inhibited when working within a format with which they are already familiar from everyday life.

\subsection{Web 2.0 as a Tool for Cultural Learning}

Finally, the question remains how the incorporation of Web 2.0 in the foreign language classroom influences cultural learning. As various studies that were mentioned earlier showed, 
students have access to authentic materials through Web 2.0 applications and have an opportunity to interact with native speakers in an authentic context. Both of these factors are central for cultural learning.

The study of Lee (2009) looks at cultural learning and how it is influenced by blogs and podcasts. In this study 33 learners of Spanish communicated over podcasts and blogs. Ten of the students were from the United States, 23 were native speakers of Spanish from Spain. The Spanish students were advanced speakers of English. During the study, the students were first given a small introduction to the software. Then they went through three phases of interaction. In the first phase, the students used blogs to talk about cultural aspects of their counterparts' culture. In the second phase the students communicated through podcasts. The U.S. students rehearsed the recordings and then put them online. Because the Spanish speakers experienced technical difficulties while making individual recordings, they instead put comments on a message board. In the third phase students discussed cultural differences on a message board. After the three phases were completed, the researcher conducted an interview to investigate students' level of satisfaction and asked them to explain their ratings. 
Lee (2009) found that students evaluated the learning experience positively overall. They liked the communications and felt engaged. Negative aspects were that the students would have liked more participation from their peers on the other side and that replies to posts sometimes did not arrive in a timely manner. Blogs and podcasts engaged cultural exchanges and gave the students the means for an international cultural exchange. This cultural exchange motivated the students to learn about the other culture. Their criticism that replies took too long suggests that the students experienced a great deal of anticipation with regard to the cultural exchange with their Spanish-speaking counterparts. The native-speaking readers also encouraged the students to be more careful in their own writing. They ultimately reflected more on their work than they otherwise might have, and they also experienced a low level of performance anxiety. Finally, the researcher states that this study could have been a quantitative study if they had employed a pre-test. Also Elola \& Oskoz (2008) researched the development of intercultural competence through blogging exchanges. Their study examined a virtual exchange between study-abroad students and at-home learners. It also examined the differences in intercultural competence between the two groups and the impact of blogs on intercultural development between the two groups. 
The at-home group consisted of 23 U.S. students of Spanish in their third semester of Spanish instruction on an exchange trip in spain. The second group consisted of 15 U.S. students in their third semester of Spanish who had stayed in the U.S. Both groups answered questionnaires at the beginning and end of the semester. The U.S. students had culture lessons during their classes, whereas the students abroad had firsthand cultural resources. Both groups were instructed to use blogs. The blogging project had distinctive phases. First, the students in the U.S. discussed a topic in class. They then had to find a research topic, which they chose from a pool of five themes. Third, they discussed these topics with the students in spain; all students engaged in the dialogue. Finally, the at-home students gave a presentation on their findings in class to their peers and teacher.

Elola and Oskoz (2008) discovered, that both groups not only gained insight into the foreign culture, but they also compared the culture to their own. The at-home students were interested in the way of life in Spain and the students in Spain answered their questions. The at-home students also worked out cultural misunderstandings and showed interest in cultural diversity. Information on cultural differences and especially diverse insights from multiple sources about these cultural differences were harder to get for them outside the culture, but 
the at-home students willingly changed their perspectives when they were in error. Both groups' cultural awareness benefited from the blogging interaction. They continually re-evaluated their perspectives and reflected deeply on culture throughout the blogging experience.

The researchers state that it would be interesting to see a larger group of participants in a similar project. Overall, this study gives deep insight into the cultural development of students who use Web 2.0 interaction to foster their cultural knowledge by describing an innovative and unique project in which students collaborated internationally through a Web 2.0 platform. The description of the participants and their circumstances is rich and easy to follow.

These studies show that Web 2.0 learning environments are a great vehicle for cultural learning. Blogs enable students who are not able to study abroad to take part in cultural exchanges. Students likewise exhibit a lower level of performance anxiety within the blog while still paying close attention to their own writing process. Web 2.0 gives students the chance to view the target culture from an outsider perspective and to draw crosscultural comparisons. 


\subsection{Discussion}

The previous review of literature has shown a variety of findings, grouped under five themes: The history of ComputerAssisted Language Learning and its relation to Web 2.0 ; Web 2.0 applications as an educational resource; motivating factors of Web 2.0 in the classroom; the role of the audience, and cultural learning.

The first theme is of a pedagogical and theoretical nature. It illustrates basic principles that apply to all Web 2.0 applications. Earlier findings, introduced by Warschauer (1997), related to pre- Web 2.0 technologies but are still highly relevant. Web 2.0 technologies have raised interaction among users to a whole new level; students do not only interact with a single teacher as in teacher-centered instruction or non-Web 2.0-based instruction. Instead, they interact with each other, which leads to an increase in their motivation, as Alm (2009) points out.

Warschauer (1997) wrote that going back in communication and focusing on single parts of a discussion in a chatenvironment was a novelty to synchronous computer-mediated communication. More than a decade later, this statement has not lost its importance. Though the medium has changed, as with blogs, it is still important that communication can refer to 
previous arguments. Also, the idea of hyper-media, an interlinked network of information, which was mentioned by Warschauer (1997), is amplified by interlinked networks of students in Web 2.0. Furthermore, the analysis of Sturm et al. (2009) has shown that Web 2.0 tools match the constructivist theory of learning. Authenticity, active use of material, the teacher role as a facilitator of learning and the methodical animation for critical thinking and reflection are all fundamentals of constructivist learning that are offered by Web 2.0 .

Many of the research studies focusing on wikis, blogs and audioblogs indicated their efficacy in the foreign language classroom and their positive effect on student motivation to learn. Wikis foster a foundation for collaborative writing (Elola \& Oskoz, 2010), which does not focus as much on grammar, as it does on planning, text organization and structure. Students peer edit each other (Kessler, 2009) and are not reluctant to criticize their peers. According to Kessler (2009), students view writing in a wiki as informal, which results in a reduced focus on form. Especially interesting is the finding by Elola and Oskoz (2010) that students feel more comfortable writing outside the wiki but produce better products in the wiki. This finding is in conflict with other studies, like Lee (2009), who found that blogs reduced performance anxiety. 
However, according to Elola and Oskoz (2010), students might feel reluctant to use a new medium for their writing but become accustomed to the wikis. The ultimate result of a better quality of student products cannot be underestimated because learner anxiety is usually the cause of weaker student products.

The studies also provide interesting insights into the use of blogs in foreign language instruction. Campbell (2003) has listed the different didactical approaches to blogs, while Ducate (2008) discussed the different stages students go through when they engage in blog reading and writing. xie et al. (2010) went a step further and analyzed different starter styles in a blog-based discussion. Overall, it can be said that weblogs have been subject to a wide variety of research, and it has been found that students believe their writing skills improve when using blogs. The use of blogs inspires students to identify more with the writer of literary works and the readers in their audience, and blogs are enjoyable for students (Ducate, 2008). Hsu et al. (2008) determines that with audio-blogs, like written blogs, comments are the center of blogging in the classroom. Although evaluating comments is time-consuming for the teacher, blogs provide a rich framework for student-to-student and student-to-teacher interaction. Without a comment function, however, interaction and peer feedback and editing cannot take place, which is one of the main flaws of Hsu et al. (2008). 
Web 2.0 features, from which language learners benefit, are not application-bound but can be attributed to a wide variety of Web 2.0 applications. The first factor, which was analyzed in the previous review, is the influence of Web 2.0 applications on motivation. Ducate's (2008) students stated that blogging was enjoyable, and the study of Wang et al. (2010) underscores this finding. Their students felt involved and connected to the task, and blogging had an overall positive effect on student motivation. Pop (2009) points out that students find material presented in Web 2.0 applications more appealing and structured than traditional teaching materials. Alm (2009) explains that students are motivated by their curiosity to explore new knowledge in Web 2.0 formats. Furthermore, students work autonomously in Web 2.0 environments because they can relate the task to real-life situations and also regard it as important. Web 2.0's high level of authenticity has a positive effect on student motivation (Alm, 2009). A challenge, that has been pointed out by Alm (2009) and Benito-Ruiz (2009) is the flood of information that Web 2.0 might release on its users. Benito-Ruiz (2009) recommends the use of RSS feeds to correct this problem, but Wang et al. (2009) suggests that the teacher can provide the students with a filter through which to search Web 2.0 to find valid information. Ultimately, the teacher prevents students from getting lost in a flood of information. 
According to Alm (2009) the authentic audience that students interact with on Web 2.0 is a major motivational factor. This notion of audience is of great importance when using Web 2.0 for language teaching. Raith (2006) found that compared to traditional journals, student-produced weblogs are typically of higher quality. This is based on the fact that students are aware of the presence of an outside audience, whether it consists of other students or contributors from outside the classroom. This awareness causes the students to deliver products of a higher quality. By feeling the urge to fulfill the demands of this discourse community, students focus more deeply on their writing, and they also feel involved (Wang et al., 2010) and personally connected to the task (Raith, 2006). Kuteeva (2011) also found that students, when writing in an essay-assignment, invite the discourse community to take part in the discussion and to contribute to the respective post. Finally, studies on the influence of the use of Web 2.0 tools on cultural learning show that the interactive and spaceindependent (Wang et al., 2010) nature of Web 2.0 applications makes them a powerful tool for cultural interaction. The studies by Lee (2009) and Elola and Oskoz (2008) give strong evidence of this usefulness by showing that through the use of Web 2.0 tools, it is possible to give students firsthand cultural knowledge, which they can otherwise only gain by visiting a 
foreign country. All students gained an insight into the foreign culture through their interactions with speakers embedded in the respective cultures. The students of Elola and Oskoz (2008) and Ducate (2008) felt their cultural knowledge increase. Students from both studies found cultural similarities and eliminated cultural misunderstandings. Students showed interest in the foreign culture (Elola \& Oskoz,2008) and especially focused on information from the foreign culture that they could only obtain from firsthand sources.

After evaluating information on teaching foreign languages with Web 2.0 that is either application-bound or present throughout every Web 2.0 application, the question remains, whether the results of some exercises or projects that were introduced in this chapter are as application-bound as they seem to be or if their pedagogical implications could be transferred to other Web 2.0 applications. The next chapter will answer this question by relating Web 2.0 foreign language learning to the Standards for Foreign Language Learning and illustrating the ways in which all Web 2.0 technologies can maximize culturally authentic and motivating instructional methods in the classroom and instill in students to take learning beyond the boundaries of the classroom. 


\section{Relating Web 2.0 to the Standards for Foreign Language Learning}

The Standards for Foreign Language Learning (ACTFL et al., 1996) have shaped foreign language instruction since their publication in 1996. They clearly define expectations of students at all levels of instruction and serve as guidelines for teachers in the field. The standards are categorized into the "Five Cs of Foreign Language Education" (see Appendix E), namely, “Communication, Cultures, Connections, Comparisons and Communities" (ACTFL et al., 1996, p. 3). Each of the Five Cs are broken into subcategories in which student learning outcomes are more explicitly described so they can be easily applied to classroom instruction. While the learning outcomes are more concrete than the "C" headings themselves they are still broad enough to allow for individual states to list specific skills and language functions that students need to know.

Although Web 2.0 came into being ten years after the standards were originally published, the technology provides an ideal medium through which teachers can maximize the application of the standards in their classrooms. At the same time, they can develop in students important 21 st-century skills by helping them learn how to incorporate these technologies into their learning. This chapter investigates how Web 2.0 can support 
students' achievement of the standards and help teachers make their classroom teaching more culturally authentic and motivating for students. In addition to providing the findings from research, this chapter will also give practical examples of how Web 2.0 applications relate to the standards.

\subsection{Communication}

The first "C," the Communication standard, is labeled "the heart of foreign language studies" (ACTFL et al., 1996, p. 3) and is subdivided into the sub-headings of students' conversational engagement, students' understanding of communication and the presentation "of information, concepts, and ideas to an audience of listeners or readers on a variety of topics" (ACTFL et al., 1996, p.3).

Considering Standard 1.1, the engagement in conversations is of central importance to Web 2.0 applications. In blogs, students communicate through the commentary function, in wikis they meta-talk about the product in the commentary function, and students peer edit their findings, as Kessler (2009) points out. The whole concept of Web 2.0 is about collective intelligence and the constant development of content through the work of a variety of authors. In this way, web 2.0 communication aligns 
with the Communication standard. The success of Web technologies rests upon the communication between users; without it, the technology itself could not be termed Web 2.0 .

The process of collaborative knowledge is not unique to only a single Web 2.0 application; it is the basis of all Web 2.0 technologies. The comprehensive feature of collaboration in Web 2.0 makes its process unique among forms of communication. The communicative feature is an aspect of the technology that foreign language teachers will find extremely useful in their classroom teaching. The fundaments of communication and thereby the philosophy of the Communication standard is at the very heart of every Web 2.0 application. The amount and degree of communication between language speakers is not always the same in every Web 2.0 environment, and the type of communication may vary. Students can communicate in a written form or through spoken language; however, the important point is that they express their ideas and feelings in the target language. The choice of Web 2.0 applications as a vehicle for communication is, therefore, as ample as the variety of platforms in existence.

In addition to being at the center of Web 2.0 interactions, communication is also facilitated in new and innovative ways in Web 2.0 applications. Even at an early stage, the internet provided its users with new ways of long-distance communication 
in short periods of time, for example, through email, web forums and chats. In Web 2.0 , several factors come together, which make communication easier and more entertaining than these older webservices. In Web 2.0 applications communication can be facilitated through multiple channels at once. By merging several services together, communication can happen on a textbased, audio, and visual bases all at the same time. A blog post, for example, may not only consist of pure text, like an email, but instead have text, pictures, sound files and videos that can all be accessed by the producer and the consumer of the $\mathrm{blog}$

For foreign language learners this reveals a whole new dimension of communication to be explored through the target language. Learners are able to use technologies, with which they are, for the most part, already familiar. In addition, they are able to interact with the target culture and its language speakers directly, without the involvement of the teacher. At the same time, the messages learners send and receive during Web 2.0 communication may consist of multiple kinds of media-based input, which gives language learners the opportunity not only to perceive input through multiple forms but also to address multiple audiences (peers, teachers, native speakers, etc). Another dimension of communication in Web 2.0 is that it can better address different learner types. Whereas more 
traditional online media, such as chatrooms, are often restricted to only a single form of input, the written word, which would benefit primarily visual and auditory learners (Gass \& Selinker, 2008, p. 564), the multiple communicative possibilities in Web 2.0 can give language learners the opportunity to access input that fit their learning style best. An auditory learner can listen to spoken language or record his or her voice to then have an acoustic, authentic interaction with a native speaker. Letting the students record a podcast, through which other learners can interact with them, can foster this communication.

Finally, Web 2.0 simplifies the teaching mission of the teacher, who in the past had to transport cartons of realia from the target culture to the classroom; now multiple cultures in which the target language is spoken can be reached by the click of a mouse button.

In theory, the ability to address multiple kinds of communication at the same time is not necessarily new to web 2.0. Earlier websites could just as well implement these features through a system of links, and students could get diverse input sources by clicking on them. It was, however, impossible for students to become participants in the communication process. If they wanted to post an answer to a website, they had to have their own website, for which they 
needed special knowledge to create. Because Web 2.0 platforms are geared toward user-friendliness, they support diverse channels of communication that can be employed by the most basic users.

Communication Standard 1.2 states that students should be able to "understand and interpret written and spoken language on a variety of topics" (ACTFL et al., 1996, p.5). Given the fact that the internet provides foreign language learners with a virtually infinite number of authentic resources with which they can practice, Web 2.0 directly enhances the communication aspect of this standard. It provides authentic written materials, as well as listening materials that students can analyze, interpret, discuss, and respond to, often in live time. Authentic material can also be mediated to learners at all levels via sites such as www.eslpod.com, which features authentic podcasts as a resource to address the challenges that students at different levels face. While additional materials can be created to accompany these podcasts for further language learning, the podcasts themselves can function as a basis for communication among students. Compared to listening to a recording or a newscast, podcasts have various features that make them easier for language learners to use and revisit. First, they can be downloaded and then uploaded to a mobile listening device for place-independent listening and learning. 
Second, they can be implemented into the students' Web 2.0 space, which may be a blog or other similar site. From the site, the podcast may be discussed by other learner peers or native speakers who take part in the discussion. Third, podcasts may have a commentary function themselves, which encourages spoken interaction between the creator of the podcast and the audience. Also, a visual learner can be especially accommodated by the large variety of videos found on youtube. The above-listed interactional advantages for podcasts are also applicable to youtube videos. Finally, the immense variety of different authentic resources that Web 2.0 provides make it a great source for material to which students can relate.

Standard 1.3 states that "Students present information, concepts, and ideas to an audience of listeners or readers on a variety of topics" (ACTFL et al., 1996, p.5). When using Web 2.0 applications, students can create a personal virtual space within the application, for example, a blog, podcast, or Twitter-feed, or they join a community of learners in collaborative content creation, as in a wiki. Students can also participate in commentary-based discourse on a blog or in any other Web 2.0 platform that allows comments. In both of these environments, whether creating or participating, students have the ability to shape their content according to the medium while still retaining a presentational style that is as authentic for 
the format in which the content appears. Another strength of such presentations is that the students are more likely to experiment with material and work more creatively because of the increased motivation that Web 2.0 applications inspire in the learner. Finally, if a student, for example, posts an article on a blog, he or she can enrich the blog-post by adding authentic multimedia content, like a youtube video, a picture or a podcast to the text.

\subsection{Culture}

The second "C" of the Five Cs refers to Culture. According to this standard, students are able to "demonstrate an understanding of the relationship between the perspectives of the culture studied" (ACTFL et al., 1996, p. 6). As found by Wang et al. (2010), Lee (2009) and Elola \& Oskoz (2008), Web 2.0 language instruction is a strong tool for cultural learning. Through Web 2.0 applications students have the opportunity to interact with authentic cultural natives of the respective language. This provides them with a first-hand insight into the target culture that is otherwise hard to achieve from outside the target culture or in the classroom. 
An example of a cultural exchange could be a blogging project about the fall of the Berlin wall by students who study German as a foreign language. By directly interacting with native speakers and asking them for their opinions and feelings about the fall of the Berlin Wall, students would gain a detailed cultural insight into German history and an authentic view of people's perceptions and emotions about a recent piece of history that had a great impact on German culture. This project could be related to different contexts in recent history and greatly enrich student's cultural knowledge because their comments, along with those of others, are published on the web, they likewise contribute to cultural products that have been created to document the event.

The importance of understanding cultural products and their unique link to the target culture is emphasized in standard 2.2. The application of this standard can be exemplified by the Abrams (2002) study, in which college level students of German at a U.S. university used a web-forum to discuss online with Germans cultural stereotypes of both cultures. The researcher concludes that the U.S. students who took part in this exchange gained a deeper insight into the German culture and could successfully eliminate false assumptions about the target culture by discussing them with the native speakers through the web platform. These insights, that 
came directly from an insider of the culture, a native speaker, were mediated in a fast and live format through the possible in such an immediate, live interaction through the technologies used in the project. A control-group that was not exposed to the web-exchange could not provide the same insights because they did not have the same access to native speakers. Students that engaged in conversation with native speakers successfully understood perspectives typically only available to insiders of that culture.

The study by Abrams (2002) predates the advent of Web 2.0 technologies. However, web forums have a lot of features in common with Web 2.0 tools. Once given access, long-distance communication on a text-basis can be established in a web forum just as well as in a blog. People can comment on previously made statements just like in a blog. However, there is a crucial difference between web forums and blogs: web forums are less accessible, and they cannot provide the same level of multimedia integration as a blog. Accordingly, the already positive features, which lead to a high degree of cultural learning in web forums, can ultimately be enhanced by weblogs in Web 2.0. In conclusion, Web 2.0 is an essential tool at the teacher's fingertips for enhancing students' cultural learning, and it can provide opportunities not available in previous, low-tech classrooms. First, the number of native speakers who participate 
in discussions about their culture via blogs, podcasts, and tweets etc. is much higher than the limited group of people who access a web-forum. By joining a Web 2.0 community, which may consist of different interlinked sites, students can gain a wider perspective on authentic cultural material and allow for the interaction between readers and authors of the cultural products by comment-interaction. The number of possible cultural exchanges is virtually unlimited.

The nature of cultural exchanges can also be enhanced. Whereas students need special knowledge about the technology in a web forum (multimedia cannot always be implemented, it is also often necessary to use code-language to do so), Web 2.0 platforms feature ample opportunity to include other media in the discussion, such as, for example, videos from youtube, pictures or podcasts, which in most cases can be added by the click of a single button in Web 2.0 applications rather than by implementing code in Web 1.0 websites. Many Web 2.0 platforms, such as blogging services like blogger.com, wordpress.com or tumblr.com, are equipped with the ability to easily include these multimedia posts in posts on their own system. This multimedia enrichment can lead to deeper discussions and more diverse discourse among students of different cultures and can open new culturally authentic perspectives to learners. 
It is, however, important to make sure that students do not use these tools to form a collection of language bits to make statements. It is crucial that students use this input to enhance their own language presentation, rather than rearranging what is already available for them on the web. They have to be made aware of the risks of plagiarism in an age when media allows for the easy cutting and pasting of what appears to be general knowledge but is, in fact, individual intellectual property

\subsection{Connections}

The third "C," Connections, refers to the link between a foreign language and knowledge in other disciplines, as well as cultural comparisons. Foremost, Web 2.0 forms a strong connection to the area of technology and the acquisition of important $21^{\text {st }}$ century skills. In Web 2.0 students not only learn the language but also learn how to use a variety of web-based programs and applications in which they can put their language skills to use. For example, they learn how to structure a website which to them is a genre of writing. They also learn how to display their content to the audience in an appealing way through their design of choice. The possibility to use multiple 
forms of media at the same time to convey meaning through language is also a skill that, in a society that is more and more digitalized every day, is very useful to students. A good example of this multimedia genre is the current development in people's reading habits. More and more people read their books on an interactive e-reader than in a book. These books are, if they are optimized for colored screen readers, not only textbased but also contain pictures and video at the same time, which enrich the reading experience. When students build their Web 2.0 content, they learn how to arrange and design multimedia content at the same time. Therefore, students not only become more language literate, they at the same time become more technology-literate, which will be a crucial skill for their lives. They also relate to art-related disciplines by maintaining their own website and picking a design for their Web 2.0 presence. They learn to shift through material and to ask the right questions. When interpreting the content and intent of messages on the many sites available on the web, they are thereby developing important media literacy skills. Finally, they also learn basic organizational skills by covering a lot of material and learning to prepare it down to a manageable level that can be easily placed on their own website.

A positive effect of Web 2.0 in this respect is that these multi-media content sites can be created easily. It is easy for 
students to record a video with their smartphones and then upload it to youtube for free, whereas more traditional methods of borrowing a video camera, converting the video to a digital format, finding a host website for the video and then building static presentational content around the video, which was the process in Web 1.0 , was very inconvenient for students. This complicated process also did not leave a lot of space for language learning because students had to focus so much on the area that was connected to language learning. In Web 2.0 students can use multi-media applications and at the same time still focus on their language.

Students can, for example, use a blog search engine like google blog search or technorati.com to search for authentic material in a blog on a different area of research. Following the model of Ducate (2008), students can become familiar with a blogger, analyze the blog itself and then start a comment-based discussion about their topic of choice with the native speaker as a possible expert in the field. A second possibility for students is to focus on a wiki-article about their research topic, which is written in the target language. Students can join the discussion platforms on a wiki about their topic of choice in the target language and elaborate on the content of the wiki article. The teacher could provide them with a choice of articles that are related to other disciplines that the 
students study and let them choose an article to discuss in a Web 2.0 setting. In this way, foreign language learning and other disciplines are connected to each other within Web 2.0 applications. This development enhances Gonglewski's (1999) statement about pre- Web 2.0 internet sources for making connections to other cultures. In the article she points out that the internet features a great deal of up-to-date information that is not available in textbooks. The notion of collective knowledge in Web 2.0 has enhanced this phenomenon, and it is now easier than ever to find authentic information. The study of literature and language arts can be enhanced in similar ways. Students can connect to literature in completely new ways by using Web 2.0 technology. They are able not only to find resources, but also to be part of an authentic discourse community in wikis or blog communities. For example, they can discuss their own approaches to the interpretation of literature and its themes in a wiki post. If their topic, for example, is a piece by Goethe, students can start a conversation on their interpretation of a part from the piece on their blog and invite other people to communicate with them through the Web 2.0 platform. Outside sources can be students from other schools with similar topics or native speakers. Learners might even be able to track down academic literary scholars and invite them to join their conversation. This is an especially powerful tool if 
the piece of literature that the students focus on is an older piece because many classics in literature are available for free online simply because their copyright protection ran out over the years.

Finally, because students work creatively on their own sites, they develop knowledge of disciplines such as art and design. They learn how to organize information and place it onto a page in an easily digested form. They learn to sift through material and to ask the right questions when interpreting the content and intent of messages on the many sites available on the web, thereby developing important media literacy skills.

\section{4 Comparisons}

'Comparisons' is the fourth "C" of the standards and highlights the student's ability to compare the target language and culture with their own. In this standard, students are supposed to find similarities and differences between linguistic features of their first language and the target language. They are also supposed to point out cultural differences between their own culture and the target culture. As Elola and Oskoz (2008) point out, such comparisons can take place in collaborative virtual study abroad programs in which at-home 
students compare their own cultural environment to the cultural insights they received from study-abroad students through weblog-based communication. Through this communication, both groups increased their "understandings of cross-cultural information and perspectives" (Elola \& Oskoz, 2008, p. 472). Thus, students are able to compare personal and cultural views from the target culture to their own culture by receiving authentic and live input from native speakers or peers abroad and, therefore, gain firsthand information about the culture that is not available in their immediate surroundings. This exchange and comparison is unique to Web 2.0 because it is not limited to a certain number of occasions, meaning a limited number of days during which the native speaker partners are available in the chatroom. Instead, the input can come from an endless source of native communicators who are creating content on various Web 2.0 platforms. Students may, for example, interact with a community of native speakers on the discussion sites of a Wikipedia article and discuss different aspects of culture in order to incorporate it into the encyclopedia. In that environment the number of contributors can become quite high simply because Wikipedia is extremely popular throughout the world. The diversity of the material that learners gain through these interactions enables them to compare their insights to their own culture and language. A discussion within 
the Wikipedia discussion sites also enables them to experience different points of view within the target culture on their topic of choice. This is especially important because students are exposed to authentic language and are, therefore, able to see how native speakers formulate sentences to talk about a particular topic. In addition, learners are exposed to a great deal of informal language and slang in blogs and comment threads that respond to shared items of pop culture, such as youtube clips.

\subsection{Communities}

The fifth and last "C," Communities, states that "students use the language both within and beyond the school setting" (ACTFL et al., 1996, p. 7). Web 2.0 applications are ideal in helping students to realize the expectations of this standard because they can be accessed outside of class and virtually anywhere. The availability of the technologies encourages students to go beyond the demands of individual assignments to continue to explore. Students also interact with the discourse community during their free time, and, therefore, willingly pursue learning outside of the classroom. Many Web 2.0 platforms have even made their way from local computers to the world of 
mobile internet over smartphones, making instantaneous and authentic communication a possibility for learners at any place and any time.

Because Web 2.0 interaction is motivating for learners, and because they see that communication in Web 2.0 is authentic and meaningful, they will likely be motivated to extend their foreign language communication beyond the classroom to wherever they are. An example of this process is the use of Twitter for communication with native speakers. Students are able not only to send and receive tweets when they check a website at home or from school, but in a text-message-like manner, they can send messages over their smartphones, which is an extremely authentic context in the target language. Communication with the native speaker would feel less strange or foreign to them because they use the technological format on a daily basis to communicate with their peers. An ultimate challenge for learners is mastering the unique language used in text messages and on comment boards. This is a skill, however, that can be developed over time.

The standard states furthermore that language learning should go beyond classroom instruction itself and lead to lifelong learning of the language (ACTFL, 1996). Because all Web 2.0 applications that are used for foreign language instruction involve a real-life setting based on the nature of the medium, 
Web 2.0 encourages students to use their language skills for their own learning beyond the classroom. Because they know how to use the technology and access the authentic, target-language sites, they are well equipped to continue the discovery process when they are outside of the school setting.

This chapter has shown that Web 2.0 is an excellent tool for the teaching of foreign languages. However, it still remains a tool among others and cannot facilitate language learning by itself. Teaching a foreign language using Web 2.0 can, however, help teachers to meet the National Standards for the Teaching of Foreign Languages, in a manageable, creative, and motivating way. Web 2.0 is able to empower students to communicate, to acquire important cultural knowledge, to connect with other areas in which the language could be used, to compare their own language and culture to the target language and culture and, finally, to engage students to participate in communities of practice beyond the limits of the foreign language classroom. This chapter has shown that communication is at the very heart of foreign language learning and also a central process in Web 2.0. The next chapter will investigate how communication, which is categorized into three modes by Swender and Duncan (1998), is facilitated through Web 2.0. Chapter four will finally show how to address these three modes of communication 
and give specific examples for teachers to implement Web 2.0 applications into their teaching by using web 2.0 applications.

\section{The standards-based Foreign Language Instruction and Web 2.0: \\ A Praxis-oriented Approach}

Chapter Three demonstrates the theoretical bases for using Web 2.0 applications to align foreign language instruction with the National Standards. This chapter provides instructional examples of standards-based language instruction using Web 2.0 and aligns them with the modes of communication: the interpretive, the interpersonal and the presentational (Swender \& Duncan, 1998). These three modes of communication often go along with teaching according to the standards for foreign language teaching, which was proven to be extensively addressable by teaching with Web 2.0 applications.

\subsection{The Three Modes of Communication}

Unlike the previous chapters, which based their insights and arguments on Web 2.0 applications that were well researched, this chapter introduces three new Web 2.0 applications about 
which there is little research about their uses for the foreign language classroom. I examine the programs voicethread.com, tinychat.com and xtranormal.com and show their relationship to the modes of communication by linking them in a thematic unit of instruction, which teachers of foreign languages can directly use in their teaching. This thematic unit will show that teaching with Web 2.0 applications is a strong complement to teaching according to both: modes of communication and the National Standards for the teaching of foreign languages. All materials that are used in the thematic units along with sample lesson plans can be found in the Appendix.

First, it is crucial to understand the distinction Swender and Duncan (1998) made between the three modes of communication: interpretive, interpersonal, and presentational. The authors point out that the traditional model of categorizing language use into reading, writing, speaking, and listening skills was outdated and argue instead that communication can be categorized more holistically into three interdependent categories.

The interpretive mode refers to the cultural interpretation of language in spoken and written form. The difference between interpretive and interpersonal communication is, that it is not possible for the communicators to negotiate meaning because the interlocutor or producer of the text is not available to respond. It refers to more than just reading and listening, 
which serve as the vehicle for the understanding process, but also cultural understanding. "The more one knows about the other language and culture, the greater the chances of creating the appropriate cultural interpretation of a written or spoken text" (Swender \& Duncan, 1998, p. 3). The authors underscore that reading between the lines is a skill that is learned at slower pace. An interpretive task requires learners to read an authentic text and interpret its meaning using skills such as summarizing, analyzing, deducing, and inferring. The reading student then deducts the authentic meaning from the text and produces a response to the text in which he or she interprets the source.

In the Web 2.0 classroom interpretive communication can have various manifestations. As Web 2.0 delivers an almost endless variety of authentic written, spoken, and audiovisual sources, it at the same time delivers these as opportunities for students to communicate in the interpretive mode. It could, for example, be possible to let the students watch an authentic video from youtube.com, which introduces a certain aspect of culture. In this chapter, videos are going to be a part of a the thematic unit, in which students will watch a sequence of authentic video material to interpret the video's cultural implications, summarize the information, analyze it and deduct their cultural value for their authentic teaching situation. 
Web 2.0 can complement interpretive communication in various more ways. It is a clear advantage of Web 2.0-based instruction that it can provide that mass of authentic material, which is constantly updated. More traditional media cannot achieve this degree of availability and authenticity. It is unique to Web 2.0 .

The second mode of communication is the interpersonal mode. It is characterized by an active negotiation of meaning among individuals, which has to be spontaneous and unplanned communication (Swender \& Duncan, 1998, p. 3). It describes a communicative interaction between two or more individuals during which the communicators monitor and observe their language, make adjustments and clarify (Swender \& Duncan, 2008). According to the authors, this mode also leads to the highest level of successful communication among the three modes because of its immediacy and spontaneity. It can be achieved not only through direct communication, but also through reading and writing in different media.

Web 2.0 can also complement this mode of communication. At first sight Web 2.0 applications may seem to facilitate little interpersonal communication because most of them are based on asynchronous communication. However, Web 2.0 is more than just islands of asynchronously developing communication; Web 2.0 is interlinkable and dynamic at the same time. Web 2.0 applications 
can be implemented into applications, which foster synchronous, and, therefore, spontaneous communication. One example, that will be part of the thematic Unit, is tinychat.com, which is a videoconferencing environment, in which the communicators can communicate spontaneously in real-time through a web-based platform and complement their arguments through collaboratively working on a product at the same time in the same interlinked environment. They can also add other types of media from various Web 2.0 sources, such as pictures, presentations, and short video clips. These can enhance the students' interpersonal communication through the use of authentic pieces of media. These media are cultural artifacts that add a new dimension of cultural authenticity and meaningfulness to the learners' interpersonal, communicational learning experience. They can both act and react in a conversational setting that is authentic in terms of content, style, and execution.

Finally, the presentational mode refers to the "creation of messages in a manner that facilitates interpretation by members of the other culture where no direct opportunity for the active negotiation of meaning between members of the two cultures exists" (Swender \& Duncan, 1998, p. 4). In other words, it refers to culturally valuable acts of one-way writing or speaking from a student. 
For students to produce these written or spoken pieces of one-way communication, Web 2.0 applications feature a rich variety of platforms to support the students in their creational and creative process. Generally, these platforms also allow the students to incorporate more than just one way of conveying their speech. Students can, for example, add a variety of multimedia content to their presentational communication. This multimedia aspect enhances the presentational communication both in a cultural dimension, as well as in terms of meaningfulness. This multimedia response to a presentational communication process can enhance the students' cultural experience and the authenticity of their products beyond the quality of more traditional learner products. Students can, for example, integrate several pictures, videos or products from other Web 2.0 sites, into their weblogs.

In addition to multimedia diversity, Web 2.0 has more advantages for presentational conversation when compared to traditional media. Whereas traditional paper-based media were only capable of conveying static content, which was created by a single student, Web 2.0 applications give students the power to collaborate and thereby let their products evolve over time. This process has been illustrated by several Wiki-projects. A third strength of Web 2.0 applications for presentational communication is the degree of meaningfulness that Web 2.0-based 
tasks can achieve. By facilitating presentational communication through Web 2.0 applications, students can gain important $21^{\text {st }}$ century skills. They can also be introduced through work processes, which they can later use outside of the classroom for career-related processes. Students can, for example, collaboratively create lab reports through a wiki or pieces of writing for other genres. The distinct advantage of Web 2.0 applications towards traditional media in this case is that they can collaborate easily and, therefore, gain teamwork skills. In today's society these teamwork skills are central competences, which require both, communication and $21^{\text {st }}$ century skills. In order to offer a standards-based curriculum, teachers need not only teach according to the National standards but also offer students learning opportunities and assessments in each of the modes of communication side by side with the Standards. The previous chapter showed that Web 2.0-based instruction can be very advantageous in addressing each of the standards. In addition to enabling standards-based instruction, Web 2.0 applications facilitate the use of language in all three modes of communication. As we have seen so far, Web 2.0 is enormously suitable to address all three modes of communication through its variety of authentic material, versatile and connectable applications and collaboration features. 
The goal of this chapter is, therefore, to promote a thematic unit, which provides concrete examples of how to teach the three modes of communication using Web 2.0-based foreign language teaching to exemplify one way in which web 2.0 offers various advantages towards traditional instruction. First, voicethread.com will be introduced to demonstrate a method for teaching interpretive communication. Tinychat.com will be used to facilitate interpersonal communication. Finally, students will produce a short movie with xtranormal.com as the presentational portion of the sequence and use their products for a self-created assessment assignment, which prepares them for an assessment based on the Integrated Performance Assessment by Adair-Hauck, Glisan, Koda, Swender, and Sandrock (2006), which assesses the three modes of communication in a sequence of assessments, which are aligned according to the modes. While the thesis offers a limited number of examples for in-class use, Web 2.0 technologies can be used in many different ways to provide students with the opportunity to use all of the modes of communication and produce both oral and written language. 


\subsection{Voicethread.com, tinychat.com, and xtranormal.com}

Before turning to the implementation of Web 2.0 technologies in the classroom, it is first important to get a general understanding of the tools themselves. The first tool that is used in the thematic unit below is voicethread.com. A voicethread is an online application, in which students or teachers publish an online presentation and / or react to a presentation that has already been made. Any kind of media can serve as a vehicle for voicethread presentations. The system can use sound, video, picture, text, and even whole presentationfiles. The user uploads one or multiple files, which will then be displayed inside the backend of voicethread.com. The pages resemble slides in a Power Point presentation. The user may then reorder the pages at will. When the page are in order, the user may provide voice, video or drawing comments to the slides himself and thereby, for example, invite visitors to engage in a conversation or give additional information about the topic, which could not be included in the visuals. After a voicethread is created, other users can comment on the different slides of a voicethread in different ways: they can write a comment, record a spoken answer, record a video with a webcam or even record a voice message by calling a phone service. At this point, a voicethread looks somehow similar to an embedded youtube.com 
video, but with different controls. It offers the user controls to just play the whole presentation with all the associated comments, forward and back keys, and an options menu. This menu bears options for the user to implement the voicethread into another website and, therefore, interconnect it with other Web 2 . 0 applications.

After the voicethread-creation by the original author is finished, commenting users can draw images onto the slide when they respond to the voicethread slide. These so called 'doodles' are drawn with the mouse and appear as an overlay on the respective slide, while comments are displayed or played by others. Creators of a voicethread have a variety of moderation options in a voicethread. For example, they can make their voicethread space more private if they wish and restrict other users from posting comments. While this restricts possible communication between author and user, this feature allows for a more static presentation of content while still retaining all the features of a voicethread.

Voicethreads can be implemented into other websites. By copying a code from the options menu into another website, the voicethread appears as if it were reached by browsing through voicethread.com. With this feature an author can present voicethreads outside of voicethread.com, for example, in a blog. Finally, voicethread.com offers a special mode for educational 
purposes. An instructor can buy a separate space of voicethreads for his or her students, giving him different moderating options to keep content and comments among his or her class. Unfortunately this mode is not free.

The second Web 2.0 platform that is used within the thematic unit is tinychat.com. Tinychat.com is anything but tiny. This Web 2.0 service combines synchronous computermediated communication (SCMC) with the mostly asynchronous communication of Web 2.0. Tinychat is a Web 2.0 service with which registered users can create customized chatrooms. Access can be restricted or password-protected, search engines can be restricted from listing the chatroom, and users can leave sustainable comments to the chat topic on the site. These restrictive features make tinychat.com especially useful for educators who want to keep their students in a controlled and closed environment. Users can also assign moderators, who can ban other users.

The first feature that separates tinychat.com from other chatroom providers is the possibility for conference-videochat with up to eight simultaneous participants. If users do not have a webcam, they may also voice-chat with multiple participants in the chat. To minimize sound interference, users can activate a push-to-talk function, which requires the user to push a button to enable voice submission to the chatroom. 
This video feature is rarely found in other services online. The ability to videoconference is often an extra paid feature of video-chat programs. Also, tinychat.com is not bound to extra software, whereas other videochat tools require the user to install an extra program. Because tinychat.com is not bound to any software other than a web browser and an Adobe Flash plugin, it is platform independent. However, this platform-independence does not include operating systems which do not support flash, like ios by Apple Inc. Therefore, tinychat.com cannot be used with an ipad or iphone and does not qualify overall to be used for mobile learning. However, it is compatible to all stationary computer operating systems like Macos, Linux or Windows. This makes it easier for users of different operating systems to use the program. This is also interesting for educators who want to use tinychat.com to communicate with people in other countries even though different systems might be used in different countries. However, web browsers are the same all over the world.

In addition to the video-chat feature, tinychat.com has several features that go beyond a normal chatroom environment. Users can add a youtube video to the chatroom, broadcast their own desktop to the other members of the chatroom, and attach documents. These documents are then distributed to the members of the chatroom. In addition, the participants can 
collaboratively edit them. This feature is similar to a wiki; users can return to past versions of the document, if necessary, in order to review and edit. Through this feature, foreign language learners may receive instructions or conduct work on a collaborative project while communicating synchronously in the chatroom. This inception of Web 2.0 applications into a chatsoftware is what makes tinychat.com especially interesting and useful to educators. As stated above, it allows students to enhance their interpersonal communication with the variety, cultural authenticity, and meaningfulness of Web 2.0 applications.

Another interesting feature is that users can attach a virtual white-board to the chatroom, in which they can draw in real-time and finally save the collaboratively created picture to a file, which may be attached to the chatroom as well. These extra features are mostly realized through applications outside the tinychat software itself that are interlinked and implemented into the software.

Despite the mass of features that are available through tinychat, the technology is not complicated. Tinychat's design is focused on the text and videochat function. All of the other features, except for a comment function, which lets users post a static comment under the chatroom, are grouped under a dropdownmenu so that they do not distract the user. They are easy to 
find but are out of sight when they are not needed. Overall, tinychat.com resembles a classic chatroom with a list of users on the left, controls on top and a field to type messages on the bottom. The main frame is reserved to display the content of the chat. Broadcasted videos are also above the main window. This common chatroom design makes tinychat.com easy to navigate for beginners.

The final tool that plays an important role in thematic unit presented here is xtranormal.com. Xtranormal.com offers its users opportunities to create animated short films by entering a script and adding visual emotions and animations. The short movie clips can be monologic or dialogic and are played by avatars chosen as characters by the user.

Users can also make camera and sound adjustments. For example, they can let the camera zoom in on a character or pan out to show all of the action on the screen. The user can control these camera movements or, alternatively, let the computer handle the virtual camera movement. Adding sounds to the movie is possible, too. The user has the choice of a variety of background soundscapes and music. The program uses text-tospeech technology to give voices to the characters. The text-tospeech engine is able to apply pronunciation rules for different languages, such as English, Spanish, German, Italian and others. Students can register for a free test-account and can create one 
animated short-film per account. This is, unfortunately, the biggest limitation the application has; for every product, a new account must be created. Because of its increasing popularity, xtranormal.com has switched its service from a free- to a 'freemium' concept, which means that users get a limited preview for free and are charged for long-term-use. Based on this limitation, students are not able to hold accounts for multiple xtranormal projects.

xtranormal.com provides a very unique opportunity for students to facilitate presentational communication. Preparing a script and using it to convey messages through the virtual actors of xtranormal.com automatically expose the students to a very meaningful task. They get immersed into the role of a director, who is responsible for a cartoon movie in the target language. The teacher can also have the students focus on the role of the actors and give their presentational assignments a new dimension through emotions, camera movement, choice of actors and scene. With these tools students can reach new extents of presentational communication, which would not be achievable with traditional media-based instruction.

Xtranormal.com videos can also be implemented into other websites. Therefore, they can be a part of a student's blog and can be a piece of the content and authenticity-enriching puzzle of an interlinked Web 2.0-based foreign language project. 


\subsection{Web 2.0: Concrete Examples for Classroom Teaching}

This thematic unit is designed to meet the needs of intermediate-low speakers of German based on the ACTFL oral proficiency guidelines. The activities, however, can be easily adapted and applied to different learner levels and classes.

The thematic unit was created for a course at a large state university. The course meets three times a week for fifty minutes and has a class size that ranges from 15 to 27 students. The materials for this study were created for a class of 18 learners between the ages of 20 and 24. The thematic unit covers five lessons and requires two weeks of instruction. The course is accompanied by the fifth edition of the textbook "Deutsch, $\mathrm{Na}$ Klar!" by Di Donato, Clyda and Vansant (2008) and covers chapters nine through twelve. The thematic unit covers material from chapters nine and ten, after the completion of which students are assessed. In the ninth chapter the students are taught how to use the German attributive adjective system in the context of a visit to a city. The tenth chapter covers attributive comparative and superlative forms. The book highlights the city of Dresden, which also serves as the context for the thematic unit.

Using the three Web 2.0 technologies discussed above, the thematic unit guides the students through several steps of 
cultural learning while they simultaneously work on developing skills in the three modes of communication. Each mode of communication is addressed by one of the three Web 2.0 applications: Interpretive communication is facilitated through voicethread.com, interpersonal communication through tinychat.com, and the presentational mode through xtranormal.com. At the end of the thematic unit, students create a peer assessment to accompany their presentational product, which assesses the comprehension of the material presented as well as the work done throughout the chapter of the students observing the presentation. Finally, the students are assessed through an Integrated Performance Assessment (Adair-Hauck, et al. 2006$)$

The goal of the thematic unit is to give students ample opportunity to get to know sights and cultural features of the city of Dresden. Several aspects are briefly mentioned in the beginning of the unit, which give students the opportunity to individually specialize on various sights and aspects of the city that are most interesting to them. Throughout the unit they have the opportunity to research the city of Dresden and to present their findings to their classmates, who then collaboratively elaborate and comment on the individual findings that were made in the first place. 
The main goal of the thematic unit is to demonstrate the possibilities and strong relatedness of Web 2.0-based foreign language teaching to the aligned standards and modes of communication and to give instructors a ready-to-use lesson sequence in which they can make their first steps towards incorporating Web 2.0 technology into their teaching.

As an introductory remark, it has to be mentioned that it is important that for the entire unit the instructor should ensure that students have access to a computer lab with individual workstations equipped with a headset. For the use of tinychat.com the instructor should make sure that students can work in two separate rooms or locations with individual computers that have a headset and a webcam. The instructor should have a computer workstation that is attached to a projector in order to show and explain the technologies to the students.

The first lesson begins with three videos, which are downloaded by the instructor prior to the lesson and distributed to the students in a voicethread. The instructor should make sure to include the sources, as given in the lesson plan in Appendix A in order to avoid copyright problems.

The students watch the videos individually and are given the task of noting down sights and cultural features in Dresden that seem interesting to them. This can include, for example, a 
mosque in the center of an eastern German city or the Germans' concept of a downtown area with diverse cultural features. Both of these elements appear in the videos, and the lesson plan includes a list of sights that are mentioned in the videos. The cultural features are not listed, however, because the students must choose the cultural elements that they find most intriguing to themselves in order to achieve a higher level of motivation among the students. If they can choose the cultural aspect, which appears to be the most interesting, the freedom of choice can give them a higher level of interest in the topic which then motivates them to find additional information.

After the students watch the videos, the instructor distributes handout \#1 (see Appendix B). The first handout describes voicethread.com, lists features and guides the students through the signup process at the website. After distributing the handout, the teacher models the account creation process on the projector and helps the student with the account creation, if needed. After the students have signed up for an account, they are asked to post their first comment on the voicethread site, which also contains the videos. They first watch the videos and then list the cultural features and sights that they see.

In this task, interpretive communication is facilitated. Whereas the first video gives visual impressions of Dresden and 
introduces a variety of sights, the second and third videos provide a virtual guided tour through the city of Dresden. From these videos, students can get an impression of the city of Dresden as it looks today.

Voicethread.com can enhance the students' interpretive communication in this task. Just showing the videos and then asking culturally important questions about the topic, voicethread.com enhances the students' interpretive work by making their interpretation a collaboration, which can then, within the system, be elaborated on. In a traditional brainstorming task, the findings of the students could not be easily transformed into a collection of knowledge, which is made possible through the comments that students post in the voicethread. By brainstorming the different sights students do not only produce a brainstormed collection of the sights but they lay the foundation for further work with their comments. They can react by adding more comments, media or 'doodles' and can, therefore, add more than just words to a patchwork of brainstormed multimedia experiences about the different sights in Dresden.

Following the brainstorming task, the students are asked to pick one of the cultural sights in Dresden and use Web 2.0 resources to further research it using the target language. By navigating through target language websites students not only 
interpret the contents of the website but they also employ important $21^{\text {st }}$-century skills. While conducting research they learn to use the internet in the target language and learn different words that are specific to websites in the target language. They also learn how to search for and extract meaningful pieces of information from web 2.0 sources, such as Wikipedia or weblogs.

Finally, at the end of the lesson, the students are asked to put together their own voicethread. In this presentational task they are asked to transform the information they found on the internet into a voicethread, which functions as a collection of information about the sights of their choice and the cultural aspects about life in Dresden.

This task transforms their knowledge that they gained through the interpretive communication during the lesson into presentational communication. Instead of answering questions about specific sources in the interpretive mode, which would be the traditional way to facilitate interpretive communication, this sequencing of modes of communication makes the task more meaningful. The students are asked to create a product, which will later be inspected and further elaborated by a greater audience, their peers.

By collecting different pieces of information on their sight of choice, they also facilitate interpretive communication 
in different ways. They can read websites, watch videos on youtube, and collect pictures to enhance their presentation in their final voicethreads through the different media. In this process the students are exposed to different kinds of interpretive communication, which is set in a highly authentic context. In addition to the communication, they also obtain $21^{\text {st }}$ century skills by learning how to search the internet for information in the foreign language and how to navigate different websites in the foreign language. This addresses the standard of connections because they connect to an area of practice that is normally outside the language classroom: the $21^{\text {st }}$ century skill to navigate websites.

Given that Web 2.0 activities are place-independent, it is possible for the students to finish their work at home. If they do not have internet access at home, students can continue their work at a school facility, such as the library. This opens not only virtual spaces but also new real learning spaces to the student.

The second lesson begins with a commenting phase. In this part of the lesson the students are asked first to comment on their peers' work and then to react to their peers' comments. In this way students have the opportunity to share their insights with other students. Students should be made aware of this phase beforehand. The task then becomes more meaningful for the 
students because they know that the final product is intended not just for the teacher but also their peers and a targetlanguage audience. Students also have the opportunity to participate in meta-talk about their products and to make suggestions for improving their peers' voicethreads. After the first commentary phase, students will have the chance to view their comments and to react to them.

This commentary phase is at the very core of Web 2.0 teaching. Interacting with one's peers in the classroom through the foreign language can be a motivating and challenging task for students. They will have to learn how to meta-talk about mistakes they made and how to appropriately address them without offending others. They also have to make sure that their comments address a valid topic. The meaningfulness of the task itself, which is gained by its authenticity and authentic audience, will increase students motivation to perform well and give them the disposition to polish their comments to be displayed publically. This is an effect that is unique to Web 2.0 and it is one of its biggest advantages towards traditional instruction. Even in a showcase activity in which students display their work, opportunity and number of commenters are limited, while these limitations do not exist in Web 2.0 tasks. Students have the opportunity to comment at their own pace and to interact with different peers simultaneously by displaying 
various voicethreads at the same time. This exposes them to more content, more ideas of peers, and more potential feedback. Following the commentary phase using voicethread, the class looks at all of the voicethreads together and elaborate on questions that might have arisen in the commentaries together. After this discussion the students should be informed about what sights Dresden has and what is special about the city.

By using voicethread.com, the standards for the teaching of foreign languages are addressed. By watching authentic movies about a German city and its culture, students gain a genuine insight into the culture and can compare different aspects to their own culture. Especially, the first video underlines this matter, because it shows different sights of Dresden and compares them to sights in other cities. Thereby the diversity of the city is exemplified and students can relate to cultural differences through this authentic presentation.

Furthermore, by commenting and critically elaborating on the comments of the other students, the communications standard is met by fostering communication on authentic topics. Also, the communities standard can be addressed through voicethread by, after the first commenting phase, extending the audience to the outside world and inviting others to participate in another discussion phase. 
The third lesson starts with an introduction to tinychat.com. The introduction is conducted in a fashion similar to the introduction to voicethread. The students receive handout \#2 (see Appendix B) and try the software on their own for a few minutes after the teacher introduced the features.

Following the introduction, the teacher asks the students to get together in pairs and splits up the group to the two classrooms. The students then meet in a tinychat, which is their virtual room of communication. They also meet in a second tinychat, which functions as the communication centre between them and the teacher. The teacher then distributes Handout \#3 (see Appendix B) to the students and asks them to read it carefully. To distribute the task, the teacher uses the attach document function in tinychat, which can be found in the upper right corner of the window.

The handout gives the students an authentic situation in which they both have to plan a free day during an upcoming exchange visit in Dresden. They are asked to choose two sights in Dresden per person from a bank of six sights. Then, they have to come to an agreement on which two of the four chosen sights to visit during their free day. They assume that their partner has not heard of their individual sights of choice and they will have to negotiate which of the two sights to visit and how to plan their day in Dresden. To persuade their partners, the 
students are supposed to enhance their content with media they find online. For this purpose they can browse the official websites of the sights, image searching applications, and online lexica, such as Wikipedia.org. Finally, the students are supposed to come up with a plan for their free day during the exchange program. To make sure that they are communicating spontaneously, they are not allowed to copy text into the chat. This task focuses on interpersonal communication and its enhancement through Web 2.0-based content. The authenticity of the task is underlined by the fact that the students are, like in the situation given on the handout, not in the same room and have to plan their time through a tinychat. This does not only give them the ability to communicate in a chatroom environment, but it also gives them the expertise to make plans in the target language while being in separate spaces. This is a skill that they could actually need in real life, which makes the task highly meaningful for the students.

The communication is made interpersonal in this task by letting the students communicate about an authentic topic in a situation, where their production is not planned. By restricting them to copy text from the sources, they are bound to paraphrase what they hear and thereby make the speech production spontaneous. 
The nature of interpersonal communication is also enhanced uniquely by using tinychat.com. Whereas it would be impossible to quickly synthesize information that the students found on the web over a distance in real life, tinychat.com gives the students the ability to share their thoughts and enrich their arguments with multimedia content. This is where the synthesis of different Web 2.0-applications, which is manifested in the tinychat interaction, is a powerful enhancement to interpersonal communication.

Furthermore, it addresses several of the standards. As the models of the modes of communication and the standards go hand in hand and are developed to fit each other, it is already obvious that communication takes place. The connections standard has also been mentioned, the students connect to a real-world activity, which would normally take place outside of the classroom. They also obtain a modern competence of planning a vacation over a distance. The cultures standard is also addressed by the authentic cultural information they obtain and talk about when finding a consensus about which sights to visit and introducing them along with the Web 2.0 enhanced media content. As they have to figure out how to get to the sights in Dresden, they have to figure out means of transportation. While they examine websites for this, they will find out that public transportation in Germany is very different to public 
transportation in their home country. They will have to compare the two and conclude how they want to react to these differences in their plans.

Additionally, the communities standard is addressed by giving them the opportunity to use this process outside of the classroom with their peers when planning a vacation.

This exercise shows that by using Web 2.0 enhanced teaching material, standards and the interpersonal mode of communication are elevated to a higher level than by using traditional paperbased media or a simple face-to-face discussion.

At the beginning of the fourth lesson the teacher shows a prepared xtranormal video, which functions as the introduction to the third application. Then the teacher distributes handout \#4 (see Appendix B) and describes the signup process and the features of xtranormal. The teacher should pay specific attention to setting the language of the character in xtranormal to the target language so that the virtual actors have the correct phonological set to pronounce their texts.

Students then have ten minutes in which they explore the software and create their first dialogue within the xtranormal editor. The teacher then distributes handout \#5 (in Appendix B), which contains the task to create an xtranormal video in which they tell a friend in their home-country about Dresden. In this presentational task, the students are supposed to incorporate 
cultural insights, which they have come across during the last lessons.

The students are expected to introduce Dresden and two sights in the city. The two characters in the xtranormal video are supposed to have a discussion about the city of Dresden and to introduce different sights. The sights and the content are chosen by the students to increase the students' personal identification with the task.

The fact that they are telling the story to a friend invites them to compare Dresden and its culture to their native culture. This specifically addresses the cultures standard in an authentic setting, which the students could face in an out of school setting. They need a channel through which they could introduce the city to friends in their home country in an interesting and interactive way. xtranormal.com is the ideal platform for this because it is very creative for students and by creating a dialogic movie, the characters can talk about a variety of things including cultural comparisons between their own and the target culture.

At the end of the lesson the students are asked to finish their xtranormal videos at home for homework and to share the URL for the video with the rest of the class. As part of the assignment, they are asked to design at least five questions about their video that will serve as a comprehension quiz for 
their peers during the presentation in the next lesson. In the final lesson, the students watch the xtranormal videos together while answering the questions about the videos.

Xtranormal.com is a versatile application to facilitate presentational communication. Students get the opportunity to create an authentic product, a short animated movie, which in this task is created for a realistic purpose with a relation to a real-life context. xtranormal bears a core advantage towards the traditional presentational mode of writing an essay. In an xtranormal video students have to pay attention to more aspects of communication than only language. Their actors have to interact with each other and students are supposed to use gestures and emotions to underline the action their actors perform. The dialogic form of the presentational communication is also a welcome change of genre because the traditional presentational assignment would be an informational essay or a letter to a friend. A dialogue also exposes the student to a different kind of presentational communication because the student has to imagine two characters and their way of interacting with each other on top of the conventional display of facts and cultural knowledge.

The implementation of xtranormal.com to facilitate presentational communication also addresses the standards. By displaying authentic cultural information through the mouths of 
the characters in the movie, the cultures standard is addressed. By focusing on character behavior in the movie the student forms a connection to the field of movie design. And finally, the authentic product has the power to motivate the student to use xtranormal for projects outside of the classroom or for their personal enjoyment.

Finally, this thematic Unit can be concluded with an Integrative Performance Assessment (IPA) (Adair-Hauck, et al., 2006). An IPA is a sequence of assessment tasks, which is in alignment with the modes of communication in the setting of a certain context. In this IPA the context is in alignment with the context from the thematic unit: big cities in German speaking countries and their sights. In this IPA, the students are communicating in meaningful and authentic settings about the city of Vienna. The three parts of the IPA can be found in Appendix C.

Each part of the IPA is generally done during a separate lesson and the students should, according to Adair-Hauck, et al. (2006) have the chance to receive feedback from the instructor before they start with the next part of the IPA in order to recognize their errors from previous parts and to learn form the feedback for the parts that follow.

The IPA first assesses interpretive performance by giving an authentic reading-task, which is taken from an authentic 
source. The text originates from a website, which introduces the city and its facets to tourists from other German speaking regions. The text is, therefore, authentic and meaningful at the same time. The students could come across a text like this if they were researching the different sights and places in Vienna. The questions are asked in their L1, English, and the students are also supposed to answer in their L1 in order to assess whether they understood the content of the text.

Second, the students are supposed to react to an authentic situation, which is described to them in the interpersonal part of the IPA. In this part the students, in pairs, are supposed to find their way through the city of Vienna by following a map. Along their journey from a drop-off sight to their hotel, they are supposed to pass as many interesting sights as possible. This task enables the students to perform spontaneous speech acts in an authentic setting. It is likely to happen that, if they travel in a German speaking country, they would need to find their way through a city with only a map at hand. Therefore, this authentic setting is meaningful to them because they obtain a real skill that they can use later on whenever they travel in a German speaking country. According to what they already did in the interpersonal assignment during the thematic unit, the students should be perfectly prepared to act out this situation spontaneously. 
Finally, their presentational performance is assessed through the IPA presentational. In this task they are expected to write a blog-post (but outside the blogging environment). They are supposed to report back to their home country about the city they have been living in for a year during a student exchange trip to Germany. This presentational assignment gives them the chance to demonstrate that they can present what they have learned about cities in Germany during the thematic unit in an authentic context, which is set closely to what they might experience when they go on a trip or exchange visit to Germany . This sequence of IPA-based assessment should give the students the opportunity to individually demonstrate their communicative proficiency in all three modes of communication in which they have been communicating throughout the thematic unit. The IPA interpersonal and presentational assignments can be graded by using the rubrics provided in Appendix D, which are adapted from the rubric provided by Shrum and Glisan (2010, p. $493)$ •

Lastly, it has to be taken into account that this thematic Unit is part of a sequence of lessons that introduce different grammatical factors. Instructors might choose to resort to nonWeb 2.0-based tasks for a more explicit grammar focus, if they like. The assessment is not Web 2.0-based because the students' performance has to be assessed in isolation. In Web 2.0 
environments they would almost always work through collaboration, which would make it difficult to assess their individual performances.

Overall, this thematic unit, however, has shown that with Web 2.0-based foreign language instruction, the modes of communication can be addressed thoroughly in a standards-based environment. While this unit is only an example, various other Web 2.0 platforms could facilitate these communicational processes. However, voicethread, tinychat and xtranormal form a powerful synergy to promote foreign language learning across all three modes of communication.

It has also shown, that Web 2.0 can be used to facilitate contextualized instruction and that it can complement a thematic Unit throughout the process of teaching all three modes of communication within the context of choice. It has also proven highly useful to give students practical situations with a reallife context in which they interact with the language and with each other through the language in all three modes of communication.

Lastly, and most importantly, Web 2.0-based foreign language teaching has shown to be more effective in a multitude of aspects when compared to teaching with traditional paperbased methods of instruction regarding the teaching of all three modes of communication. 


\section{Conclusion, limitations, and implications for future research}

In the previous pages I have illustrated how standardsbased foreign language instruction can be enhanced through the incorporation of Web 2.0 applications. First, the term Web 2.0 and its implications were defined and demonstrated. The key to understanding Web 2.0 is first getting to know its origins in Web 1.0 technologies. The first chapter in the thesis examines these earlier technologies and discusses how they set the stage for later Web 2.0 developments. These developments then shifted online content from being static single-author-based pieces of information to a dynamic, ever evolving content that is shaped by authors and viewers through collaboration. This shift has not only effected everyday use of online content but also the way foreign language education can use the internet as a source and tool for language teaching and learning.

Foreign language instructors have used web 2.0 applications for teaching various types of content in different ways. Research has found that Web 2.0 platforms can provide a forum for collaborative writing in an environment that is comfortable for students and in which they feel less obliged to be formal. This indicates that students perceive Web 2.0 as a space for language that is similar to their everyday usage, rather than an arena solely designed for academic learning that is bound to a 
classroom setting. It has also been found that students more readily criticize and peer-edit each other in web 2.0 applications, which ultimately leads to an improvement in the quality of their writing.

Another major factor why Web 2.0 is used in the foreign language classroom is based on its effect on student motivation. Research has shown that students felt more involved in the process and valued their final products more than in non-Web 2.0 foreign language-learning environments. The students also felt more curious about researching the task; this ultimately improved their motivation because they had a clear goal, a positive attitude towards the task, and above all more interest in the topic. Students also perceived Web 2.0-based foreign language instruction as more appealing to them than traditional instruction. All of these factors lead to the conclusion that Web 2.0 has strong motivating effects upon foreign-language learners.

Research has shown that another major factor that has a positive effect on foreign language learners is the knowledge that they are creating their Web 2.0 products for more than just the teacher. The students who are aware of the possibility of Web 2.0 reaching beyond the classroom are motivated by the target-language audience and the authenticity of the task. They even invite the audience to join their conversation. 
Finally, research pointed out a major advantage of Web 2.0 applications in foreign language instruction. Web 2.0 is able to support cultural learning and maximize the potential impact of the National Standards in classroom teaching and on the curriculum as a whole. Through their use of Web 2.0 technologies, students interacted directly with members of the target culture. This contact gives them the unique opportunity to interact with members of the target culture over an extended period of time and to ask questions that can lead to the correction of prior misconceptions about the target culture. Research has shown that students are motivated to ask these questions in Web 2.0 settings. This is especially valuable because it is hard for students of foreign languages to obtain this kind and level of information about the target culture. On the basis of what research had found, this thesis has explored the relationship between Web 2.0 and the National Standards for the Teaching of Foreign Languages. An analysis of integration of Web 2.0 in standards-based education demonstrate that each of the five Cs, Communication, Cultures, Connections, Comparisons, and Communities can be enhanced by Web 2.0 applications. Web 2.0 also has the capability to connect foreign language learning to competencies of other areas than just foreign language learning. Lastly, by working with Web 2.0, students obtain valuable $21^{\text {st }}$ century skills. 
Finally, this thesis has introduced a thematic unit, which provides an example for Web 2.0-based foreign language teaching based on three applications. Voicethread.com, tinychat.com and xtranormal.com all share the features that make Web 2.0 powerful for language teaching but have not been considered by research until today. The thematic unit addresses all three modes of communication. First, interpretive communication is encouraged by voicethread.com, followed by interpersonal communication in a tinychat.com environment. Finally, the students communicate in the presentational mode by creating a video with xtranormal.com. The thematic Unit is finally concluded by an Integrated Performance Assessment, which assesses the students individual communicative performance in each of the three modes of communication. The thematic unit was designed for foreign language teachers of German, but it can be easily adapted to all other languages.

This thesis has some limitations. First, there have been studies conducted to analyze the effects of Web 2.0 applications such as blogs, wikis and audioblogs on learner outcomes in foreign languages. The results of the studies that were analyzed underscore the statement that Web 2.0 is a motivating tool for foreign language learning. These studies, however, have been conducted under special circumstances with limited numbers of participants. A longitudinal study could give further insights 
into the degree to which Web 2.0 applications motivate learners, especially over longer periods of time.

Furthermore, the studies that concern cultural learning are not of great number. It would be interesting to see the results of a long-term study in which students from two different cultural backgrounds share their insights and values about their respective cultures, by using a variety of Web 2.0 tools to foster their communication. A great set of tools to use for this cultural exchange could be voicethread.com, tinychat.com and xtranormal.com, as the thematic unit has shown that they can relate to all modes of communication. A project that would extend this thematic unit across cultural boundaries and large distances would give additional insight into how powerful these three tools are for relating to all modes of communication in the foreign language classroom.

The effects on foreign language learning of the three applications highlighted in the thematic unit were not explicitly tested by research. Further research is needed to provide proof that these applications have the same effects on students as their Web 2.0 counterparts, such as weblogs, wikis, or podcasts. Given the similar communicative nature of other Web 2.0 applications, it seems clear that also the Web 2.0 applications from the thematic unit will also prevail to have the same positive effects as those applications, that have been 
researched. However, further research may reveal additional effects the three applications have on communication.

For some readers of this study, the most obvious limitation indicated by this study is that not every classroom has the necessary capabilities to facilitate learning with Web 2.0 technologies. This lack of availability of technology might still be the case in many schools throughout the world. At this point, however, it is clear that teaching with technology, and especially with Web 2.0 , is the teaching method not only for today's learners, but also especially for the more digitalized learners of tomorrow. Therefore, teaching with technology cannot be ignored by instructors simply because the technological support is not given at this point in time; it will be eventually.

A final limitation of using Web 2.0 in the classroom is that it is not always feasible for instructors to find authentic communication partners from outside the classroom to communicate with. Distance, time-zone differences and different academic schedules make international collaboration hard to realize and could pose a limitation to the usability of Web 2.0. If instructors are able to take learners beyond the classroom by using Web 2.0 technology, they will see that through increased motivation, extended cultural learning and an appreciation of an 
authentic audience and material, students' foreign language learning will benefit greatly.

Teachers in parts can also use the ideas and lesson plans from the fourth chapter. They can be used to complement more traditional instruction and are by no means supposed to replace traditional paper-based instruction. Web 2.0 methodologies are merely to be used as a complement to other methodologies. Only by combining different teaching styles and language teaching methods will it be possible to teach every learner, even those who learn better with technology and those who prefer paper and a pen. Web 2.0-based foreign language teaching is a great aid for teachers to further that variety of teaching methodology in their classrooms.

Finally, the conclusion can be drawn that Web 2.0 has the potential to support not only the foreign language learner of tomorrow, but of today. Teaching with technology is not the teaching of a time to come, it is what teachers need to consider for their students today, because they are teaching the next generation and not the past one. In terms of foreign language teaching, Web 2.0 is a powerful tool because it addresses the standards for foreign language teaching, the modes of communication, student motivation and authentic cultural exchanges and has proven to elevate foreign language 
communication in the classroom to a new level of multimedia use and interaction. 


\section{References}

Abrams, Z. I. (2002). Surfing to cross-cultural awareness: Using internet-mediated projects to explore cultural stereotypes. Foreign Language Annals, 35(2), 141-160. John Wiley \& Sons.

ACTFL, AATF, AATG, AATI, AATSP, ACL, ACTR, C. A. N.-A. (1996). National standarts for foreign language education. Retrieved 2010, from http: //www.actfl.org/i4a/pages/index.cfm?pageid=3392

Adair-Hauck, B., Glisan, E. W., Koda, K., Swender, E. B. and Sandrock, P. (2006), The Integrated Performance Assessment (IPA) : Connecting Assessment to Instruction and Learning. Foreign Language Annals, 39: 359-382.

Alessi, S. M., \& Trollip, S. R. (2001). Multimedia for learning: Methods and development. Allyn \& Bacon.

Alm, A. (2006). CALL for autonomy, competence and relatedness: Motivating language learning environments in Web 2.0. The JALT CALL Journal, 2(3), 29-38.

Benito-Ruiz, E. (2009). Infoxiation 2.0. Handbook of research on Web 2.0 and second language learning (pp. 60-79).

Campbell, A. P. (2003). Weblogs for use with ESL classes. The Internet TESL Journal. 
Davis, I. (2005). Talis, Web 2.0 and all that. Internet Alchemy.

Di Donato, R., Clyde, M. D., \& Vansant, J. (2008). Deutsch: Na klar! An introductory German course (5th ed.).

Dodge, B. (1997). Some thoughts about WebQuests. Retrieved 2010, from http://webquest.sdsu.edu/about_WebQuests.html.

Downes, S. (2009). E-learning 2.0. eLearn MAGAZINE.

Ducate, L., \& Lomicka, L. (2008). Adventures in the blogosphere: From blog readers to blog writers. Computer Assisted Language Learning, 21(1), 9-28.

Elola, I., \& Oskoz, A. (2008). Blogging: Fostering intercultural competence development in foreign language and study abroad contexts. Foreign Language Annals, 41(3), 454-477.

Elola, I., \& Oskoz, A. (2010). Collaborative writing: Fostering foreign language and writing conventions development. Language Learning \& Technology, 14(3), 51-71.

Gardner, R. C. (1985). Social psychology and second language learning: The role of attitudes and motivation.

Gonglewski, M. R. (1999). Linking the Internet to the national standards for foreign language learning. Foreign Language Annals, 32(3), 348-362. 
Handsfield, L. J., Dean, T. R., \& Cielocha, K. M. (2009).

Becoming critical consumers and producers of text: Teaching literacy with Web 1.0 and Web 2.0. The Reading Teacher, $63(1), 40-50$

Hsu, H.-Y., Wang, S.-K., \& Comac, L. (2008). Using audioblogs to assist English-language learning: an investigation into student perception. Computer Assisted Language Learning, $21(2), 181-198$

Kessler, G. (2009). Student-initiated attention to form in wikibased collaborative writing. Language Learning \& Technology, 13(1), 79-95.

Krashen, S. (1982) . Principles and practice in second language acquisition. Oxford: Pergamon Press.

Kroonenberg, N. (n.d.). Developing communicative and thinking skills via electronic mail. TESOL Journal, 4, 24-27.

Kurt, S. (2010). WebQuests and Web 2.0 screen design. Journal of Technology in Human Services, 28, 178-187.

Kuteeva, M. (2011). Wikis and academic writing: Changing the writer-reader relationship. English for Specific Purposes, $30(1), 44-57$ 
Lee, L. (2009). Promoting intercultural exchanges with blogs and podcasting: A study of Spanish-American telecollaboration. Computer Assisted Language Learning, 22(5), 425-443.

Maclean, G. R., \& Elwood, J. A. (2009). Digital natives, learner perceptions and the use of ICT. Handbook of Research on Web 2.0 and Second Language Learning (pp. 156-180).

Marcos, K. (1994). Internet for language teachers. ERIC Digest, $1-7$.

O'Reilly, T. (2005). What Is Web 2.0 Software. O'Reilly Network, $1-16$

O'Reilly, T. (2006). Web 2.0 compact definition: Trying again. Retrieved January 10, 2010, from http: //radar oreilly.com/archives/2006/12/web-20-compactdefinition-tryi.html.

Panke, S. (2007). Unterwegs im Web 2.0: Charakteristiken und Potenziale. e-teaching.org. Retrieved from ww.eteaching.org/didaktik/theorie/informelleslernen/Web2 .pdf.

Patrick, A. (2007). Facebook copyright - Have you read the small print? http://Www.broadstuff.com. 
Pop, A. (2009). Quality standard and the new technologies (NT) in higher education foreign language instruction. Annals of $D A A A M$ for 2009 \& Proceedings of the 20th International DAAAM Symposium, 20(1), 1721-1723.

Prensky, M. (2001). Digital natives, Digital immigrants.

Raith, T. (2006). Weblogs in the EFL-classroom. A study on the relationship between audience and writing. NEOS, 3(30), 330 .

Rüschoff, B. (2009). Output-oriented language learning with digital media. Handbook of Research on Web 2.0 and Second Language Learning (pp. 42-59) •

Shrum, J. L., \& Glisan, E. W. (2010). Teacher's handbook: Contextualized language instruction. Heinle Cengage Learning .

Stallman, R. (1999). The GNU operating system and the free software movement. System, (January), 1-12. O'Reilly \& Associates, Inc. Sebastopol, CA, USA.

Stevens, V. (2006). Revisiting multiliteracies in collaborative learning environments: Impact on teacher professional development. TESL-EJ, 10(2). 
Sturm, M., Kennell, T., McBride, R., \& Kelly, M. (2009). The pedagogical implications of Web 2.0. Handbook of research on Web 2.0 and second language learning, 367-384.

Swender, E., \& Duncan, G. (1998). ACTFL performance guidelines for K-12 learners. Foreign Language Annals, 31(4), 479-491.

Trotman, W. (2000). Aspects of the Internet and their Possibilities for ELT: a Survey Review. Retrieved from http: / /www.eltnewsletter.com/back/March2000/art22000.shtml.

Twitter. (2010). Twitter. Retrieved from http: //twitter.com/about.

Wang, J., Ching-Huang, W., Yueh-Chiu, F., \& Chun-Fu, L. (2010). Benefits of Web 2.0 in the college writing classroom. The International Journal of Learning, 17(2), 439-45.

Warschauer, M. (1997) . Computer-mediated collaborative learning: theory and practice. Modern language journal, 81(4), 470481 .

Weisband, S. P. (1992). Group discussion and first advocacy effects in computer-mediated and face-to-face decision making groups. Organizational Behavior and Human Decision Process, (53), 352-380. 
Würffel, N. (2008). Kooperatives Schreiben im Fremdsprachenunterricht: Potentiale des Einsatzes von Social-Software-Anwendungen am Beispiel kooperativer Online-Editoren. Zeitschrift für Interkulturellen Fremdsprachenunterricht.

Xie, Y., Ke, F., \& Sharma, P. (2010). The effects of peerinteraction styles in team blogs on students' cognitive thinking and blog participation. Journal of Educational Computing Research, 42(4), 459-479. 
Appendix

Appendix A: Lesson Plans for thematic unit 
Voicethread - Dresden

\begin{tabular}{|l|l|l|l|}
\hline Context & Sights and culture in Dresden & Material & $\bullet$ Voicethread.com \\
\hline SWBAT: & Students will be able to inform other students about sights in Dresden & & Handout \#1 \\
\hline
\end{tabular}

\begin{tabular}{|c|c|c|c|c|}
\hline Phase & Time & Details & Material & Notes \\
\hline Presentation & 15 & $\begin{array}{l}\text { The students are guided to voicethread about Dresden, which } \\
\text { contains three videos: } \\
\text { 1. http://www.youtube.com/watch?v=vHFck5e4vAO (in } \\
\text { Dresden spiegelt sich die Welt } \\
\text { 2. http://www.youtube.com/watch?v=u8TOy9QbWOQ } \\
\text { (Weltstadt Dresden) } \\
\text { 3. http://www.youtube.com/watch?v=iLi4292iQf4 (Hin } \\
\text { und Weg: Mein Dresden) } \\
\text { The students are supposed to take notes on which famous sites } \\
\text { or a culturally feature that is new to them mentioned in the } \\
\text { videos }\end{array}$ & $\begin{array}{l}\text { pre- } \\
\text { designed } \\
\text { voice thread }\end{array}$ & \\
\hline $\begin{array}{l}\text { Technological } \\
\text { introduction }\end{array}$ & 10 & $\begin{array}{l}\text { The students follow the instructions on the handout (\#1) and } \\
\text { create an account at voicethread.com. The teacher models the } \\
\text { instructions on the projector; the students follow his } \\
\text { introductions and create the account. }\end{array}$ & Handout \#1 & \\
\hline Practice 1 & 5 & $\begin{array}{l}\text { The students are supposed to post a comment under each video. } \\
\text { The comment is supposed to contain their notes from the first } \\
\text { viewing at the beginning of the class. }\end{array}$ & & \\
\hline $\begin{array}{l}\text { Application } \\
\text { phase }\end{array}$ & 10 & $\begin{array}{l}\text { Each student choses a sight or cultural feature of Dresden and } \\
\text { searches the internet for additional information about that sight } \\
\text { or cultural feature. } \\
\text { Students elaborate on their findings in their own voicethread. } \\
\text { They can post media and comment use the comment function to } \\
\text { present their findings. }\end{array}$ & & $\begin{array}{l}\text { Possible sights: } \\
\text { Video 1: Altstadt, Purobeach, } \\
\text { Russische Kirche, Jazztage, } \\
\text { Galopprennbahn, Yenidze, Barockfest. } \\
\text { Video 2: Künstlerviertel, Schlösser } \\
\text { und Residenzen, Elbe. Video 3: } \\
\text { Frauenkirche, Residenzschloss, grünes } \\
\text { Gewölbe, Milchladen, Panometer }\end{array}$ \\
\hline
\end{tabular}




\section{Voicethread - Dresden}

To prepare before class:

1. Make sure you have a computer lab for all the lessons in the unit. The students will need computers with:
a. Internet Access
b. Webcam
c. Headset

2. Create voicethread for presentation

a. Download three videos from youtube

b. Upload them into voicethread

i. Make sure, that the sequence is in order, according to the links presented in the lesson plan

ii. Make sure to provide a link to the source

c. Provide a link to the voicethread to your students. You can use http://tinyurl.com to shorten the link.

3. Copy Handout \#1 "How to use voicethread.com"

Homework:

- If students have not done so, they are supposed to finish their voicethreads.

- Students are supposed to share a link to the voicethread in a comment in the original video. 
Web 2.0 Thematic Unit Lesson 2

Voicethreads 2

\begin{tabular}{|l|l|l|l|}
\hline Context & Sights and culture in Dresden & Material & $\bullet$ Voicethread.com \\
\hline SWBAT: & $\begin{array}{l}\text { Students are introduced to a variety of sights and cultural features of Dresden. They } \\
\text { will be able to comment on them and elaborate on them. }\end{array}$ & Handout \#2 \\
\hline
\end{tabular}

\begin{tabular}{|l|l|l|l|l|}
\hline Phase & Time & Details & Material & Notes \\
\hline Commentary & 10 & $\begin{array}{l}\text { Students are asked to view their peer's voicethreads. They are } \\
\text { then supposed to leave three comments and which they } \\
\text { directly relate to their peers' voicethreads. } \\
\text { After ten minutes the students should be encouraged to go } \\
\text { back to their product and react to the comments they got by } \\
\text { commenting again. } \\
\text { The students who created the information on the different } \\
\text { sights should come up with a final response to the comments. } \\
\text { They either incorporate suggestions made in the comments or } \\
\text { react to the comments directly through another comment. }\end{array}$ & $\begin{array}{l}\text { If the students are asked to } \\
\text { provide knowledge that they do } \\
\text { not have at that point, the } \\
\text { student who was originally } \\
\text { assigned with the respective sight } \\
\text { or cultural fact should be given } \\
\text { the task to find that information } \\
\text { online and share it with the class. }\end{array}$ \\
\hline Review & 10 & $\begin{array}{l}\text { Class goes through the different voicethreads together and } \\
\text { discusses the final commented voicethreads. Teacher asks } \\
\text { students to elaborate on questions that might have arisen in } \\
\text { the commentary phase. }\end{array}$ & Voicethread.com & \\
\hline
\end{tabular}


Tinychat

\begin{tabular}{|c|c|c|c|}
\hline Context & Negotiating a plan for the day in Dresden & \multirow[t]{2}{*}{ Material } & \multirow{2}{*}{$\begin{array}{l}\text { - } \text { Tinychat.com } \\
\text { - } \text { Handout \#2 } \\
\text { - } \text { Handout \#3 online }\end{array}$} \\
\hline SW & $\begin{array}{l}\text { Students will be able to spontaneously plan and organize a short trip to Dresden in } \\
\text { an authentic setting }\end{array}$ & & \\
\hline
\end{tabular}

\begin{tabular}{|c|c|c|c|c|}
\hline Phase & Time & Details & Material & Notes \\
\hline $\begin{array}{l}\text { Technological } \\
\text { introduction }\end{array}$ & 20 & $\begin{array}{l}\text { Students are introduced to tinychat.com. Students get a handout } \\
(\# 2) \text {, which guides them through the signup process. Teacher } \\
\text { models the signup process once and lets students then sign up } \\
\text { for their own accounts. } \\
\text { Students are asked to join a common chatroom and test their } \\
\text { camera, voice and typing. If possible, students should be given } \\
\text { time to explore the software themselves within the common } \\
\text { chatroom. }\end{array}$ & Handout \#2 & $\begin{array}{l}\text { Students have to be able to take } \\
\text { their room off the public listings. } \\
\text { Students can have a combination } \\
\text { of first name plus last name initial } \\
\text { as nicknames. It is important that } \\
\text { the teacher can associate the } \\
\text { nicknames in the chatroom. }\end{array}$ \\
\hline Activity 1 & 25 & $\begin{array}{l}\text { The teacher asks the students to get into groups of two. The } \\
\text { groups are then split, whereas one half of the class goes to the } \\
\text { other room. The students then all come together in one tinychat } \\
\text { room to receive the instructions for the interpersonal task } \\
\text { through the platform itself } \\
\text { Students work according to the task and go through the } \\
\text { authentic planning of a trip to Dresden in a distance- } \\
\text { communication setting through tinychat.com }\end{array}$ & $\begin{array}{l}\text { Handout \#3 } \\
\text { online, pre- } \\
\text { defined } \\
\text { tinychat } \\
\text { room }\end{array}$ & $\begin{array}{l}\text { To make sure that the students } \\
\text { really rely on spontaneous speech } \\
\text { acts, the teacher can join the } \\
\text { students' tinychat rooms as a } \\
\text { spectator. }\end{array}$ \\
\hline
\end{tabular}

To prepare before class:

- Students will need separate rooms with computer workspaces

- The instructor should prepare a tinychat room with the task sheet attached as a document

- Copy Task \#2 for the students 
Web 2.0 Thematic Unit Lesson 4

xtranormal

\begin{tabular}{|l|l|l|l|}
\hline Context & A short documentary about Dresden & Material & $\bullet$ Xtranormal.com \\
\hline $\begin{array}{l}\text { Comm. } \\
\text { Goal: }\end{array}$ & $\begin{array}{l}\text { Students will be able to design and present a short movie clip based on a written } \\
\text { dialogue about a tour that visits several sights in Dresden }\end{array}$ & & $\bullet$ Handouts \#4 and \#5 \\
\hline
\end{tabular}

\begin{tabular}{|l|l|l|l|l|}
\hline Phase & Time & Details & Material & Notes \\
\hline $\begin{array}{l}\text { Technological } \\
\text { introduction }\end{array}$ & 2 & $\begin{array}{l}\text { The teacher shows a prepared xtranormal video to introduce the } \\
\text { technology to the students. }\end{array}$ & $\begin{array}{l}\text { The students need to be aware of } \\
\text { the fact that they are using a trial } \\
\text { account and can therefore only } \\
\text { create one movie. }\end{array}$ \\
\hline Video creation & 20 & $\begin{array}{l}\text { The teacher distributes handout \#4 and models the signup } \\
\text { process at xtranormal.com on the projector and then creates a } \\
\text { sample movie. } \\
\text { Let students familiarize with the possibilities xtranormal.com } \\
\text { gives them. Let them play with different emotions, camera angles } \\
\text { and characters. }\end{array}$ & $\begin{array}{l}\text { Histribute handout \#5. Let the students work on their videos and } \\
\text { quiz. Let them finish them at home. }\end{array}$ & Handout \#5 \\
\hline
\end{tabular}

To prepare before class:

- Prepare a short clip that tells the students about what they can do with xtranormal

- Copy handouts \#4 and \#5

Homework:

- Students need to finish the tasks in handout \#5 at home and send the URL to their video and the short quiz to the teacher. 
Web 2.0 Thematic Unit Lesson 5

Xtranormal and studentmade quizzes

\begin{tabular}{|l|l|}
\hline Context & A tour through Dresden \\
\hline Comm. & Students will be able to understand the content and cultural implications of their \\
\hline
\end{tabular}

Goal: peer's xtranormal.com videos

\begin{tabular}{|l|l|l|l|l|}
\hline Phase & Time & Details & Material & Notes \\
\hline $\begin{array}{l}\text { Xtranormal } \\
\text { presentation }\end{array}$ & 20 & The teachers and students watch the xtranormal videos & Xtranormal.com & \\
\hline Assessment & 30 & $\begin{array}{l}\text { The teacher distributes the student-made quizzes and shows } \\
\text { the xtranormal videos that match the quizzes The videos } \\
\text { should be shown twice. The students then answer the } \\
\text { questions and discuss their findings at the end. }\end{array}$ & $\begin{array}{l}\text { Xtranormal.com, } \\
\text { student videos, } \\
\text { Quizzes }\end{array}$ & \\
\hline
\end{tabular}

To prepare before class:

- Students are supposed to have sent in their videos and quizzes. The quizzes need to be copied. 
Appendix B: Handouts for thematic unit 


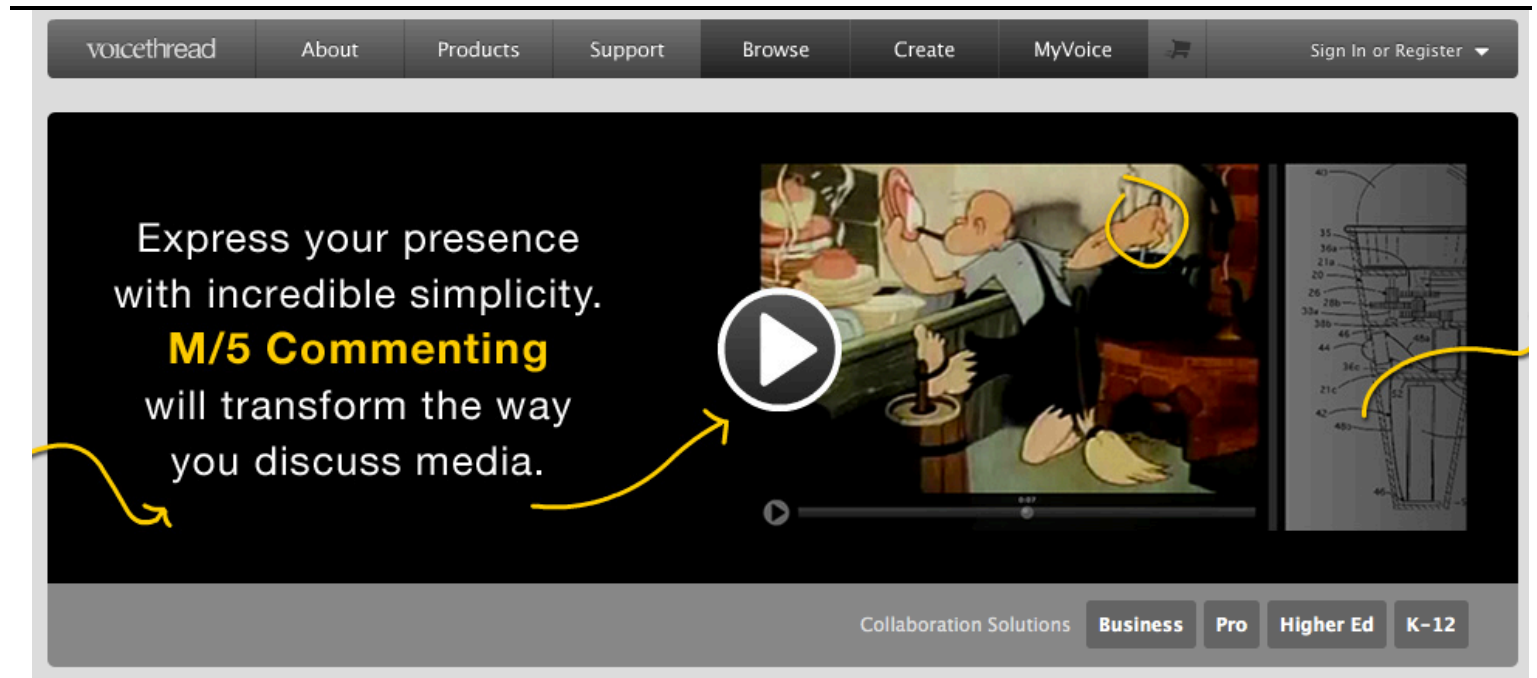

Screenshot of voicethread.com, taken on 05/30/11

What is voicethread.com ?
Voicethread.com is a website that allows users to post and discuss different pieces of media. For example, users can post a picture or video and then post comments about the picture and have other people comment, too.

You can post all kinds of media in a voicethread, for example pictures, sound files, videos or even whole Power Point presentations.

Users may also include lines that they draw with their mouse into their comments.

A step-by-step tutorial can be found at http://www.youtube.com/watch?v=-U1wIRrKyyk

- An e-mail address to verify your account

- You will be asked to create a username and a password. sign up?

How do I sign up?

What can I use voicethread.com for?

How do I create a
1. In the upper right corner, click on "Sign in or register"

2. Click on "Register" in the left clumn of the table

3. Fill in the form

4. Check your E-Mail box and click the confirmation link

- Create online presentations that include your voice

- Invite people to comment on your presentation

- Comment on presentations of other's to let the content evolve

- Use it as a creative tool to tell a story

1. Click the "create" button on the top of the page 


\begin{tabular}{|c|c|}
\hline voicethread? & $\begin{array}{l}\text { 2. Click "upload" } \\
\text { 3. Chose one of the four methods to upload a piece of } \\
\text { media "My computer" lets you browse your computer } \\
\text { a. "Mor a file to upload. You can use multiple file } \\
\text { types, as indicated on the right. } \\
\text { b. "Media Sources" lets you browse your previous } \\
\text { voicethreads, flickr albums, facebook photos } \\
\text { and sources from the New York Public Library } \\
\text { c. "URL" lets you search for media from a web- } \\
\text { address } \\
\text { d. "My Webcam" takes a video of you from your } \\
\text { webcam } \\
\text { 4. Now you can add a comment to your content. Use the } \\
\text { comments to start a conversation, give additional } \\
\text { information, or tell a story. } \\
\text { 5. Finally, you can share your voicethread with your } \\
\text { friends and invite them to participate. } \\
\text { 6. You can access your voicethreads from the "MyVoice" } \\
\text { tab on the top. } \\
\text { 7. You can share your voicethreads by clicking on the } \\
\text { "menu" icon in the top-left corner of a voicethread and } \\
\text { then clicking "share". }\end{array}$ \\
\hline Hints & $\begin{array}{l}\text { - It is up to you, if you want to share the voicethread } \\
\text { with the whole world or just with a chosen few, such as } \\
\text { your classmates. } \\
\text { - Try uploading a whole PowerPoint presentation. } \\
\text { - You can create three voicethreads on a free account } \\
\text { with a total of } 75 \text { megabytes of storage. }\end{array}$ \\
\hline
\end{tabular}




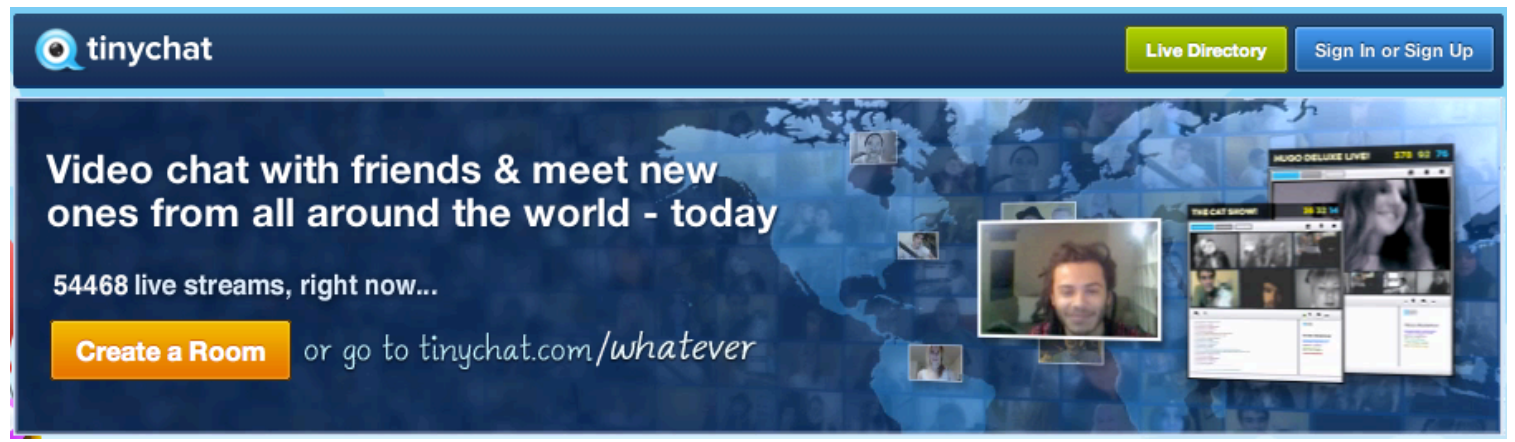

Screenshot of tinychat.com, taken on $05 / 30 / 11$

\begin{tabular}{|c|c|}
\hline $\begin{array}{l}\text { What is } \\
\text { tinychat.com? }\end{array}$ & $\begin{array}{l}\text { Tinychat.com is a Web } 2.0 \text { powered chatroom. In a } \\
\text { tinychat you can chat with text, voice and even video- } \\
\text { chat. You can also share documents, work on a } \\
\text { whiteboard, play a youtube video or show your } \\
\text { desktop to other people in the chatroom. }\end{array}$ \\
\hline $\begin{array}{l}\text { What do I } \\
\text { need to sign } \\
\text { up? }\end{array}$ & $\begin{array}{l}\text { - Nothing. If however you wish to reserve your } \\
\text { username, you need an e-mail address. }\end{array}$ \\
\hline $\begin{array}{l}\text { How do I sign } \\
\text { up? }\end{array}$ & $\begin{array}{l}\text { 5. You do not need to signup. Just enter } \\
\text { http://tinychat.com/YOURROOMNAME into your } \\
\text { browser and thereby create a chatroom. You can then } \\
\text { share the address with others. } \\
\text { 6. If you wish to create an account in order to reserve } \\
\text { your nickname for the future, click the Sign In button in } \\
\text { the top right of your browser window. } \\
\text { 7. You will only be asked for a username, a password and } \\
\text { your e-mail address. You can also use your facebook or } \\
\text { twitter login. }\end{array}$ \\
\hline $\begin{array}{l}\text { What can I use } \\
\text { tinychat.com } \\
\text { for? }\end{array}$ & $\begin{array}{l}\text { - You can use it to converse with other people over } \\
\text { distances, just like with any other chat-tool. } \\
\text { - You can video-conference for free. } \\
\text { - You can add files, whiteboards and YouTube videos to } \\
\text { the chatroom, which can be collaboratively edited. }\end{array}$ \\
\hline
\end{tabular}




\section{Web 2.0 Thematic Unit Planning a day in Dresden Handout \#3}

Task: You and your partner are going on a trip to Dresden in a month and you need to plan your one-day stay in the city. However, you cannot meet in person and are therefore using tinychat.com to plan your trip. While planning you first search the internet for possible sights and destinations in Dresden. Point out the locations of the sights and find out interesting facts about them. Find at least two sights per person.

As you advance in your planning you may find that you need to plan your stay in a detailed manner. That is why you need to scale down your plans to two sights of the original four. Share information about the sights and find out which sights the two of you want to visit the most. You can use internet resources to enhance your information such as pictures or videos.

Finally, finish your plan. Find a cheap place to stay and find out by which mean of transportation you want to get to the sights and how to get back to your over-night location. Consider a prospective budget for the trip and make it as money-efficient as possible.

After you talked about different possibilities, you may use the document- or whiteboard functions that tinychat.com

At the end of the lesson you should have come up with a plan to visit sights in Dresden for a day. The plan should be as realistic as possible and you should feel prepared to actually go to Dresden and visit the city.

You are allowed to post any kind of pictures and videos in the tinychat. However, you may not copy language passages from outside sources. If you want to use information from another website, paraphrase the information and tell your partner about it through the videochat function. 


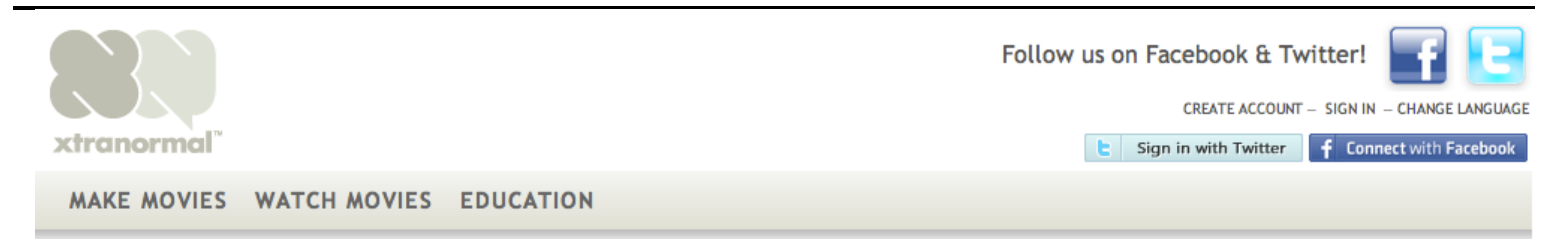

Screenshot of xtranormal.com, taken on 05/30/11

\begin{tabular}{|c|c|}
\hline $\begin{array}{l}\text { What is } \\
\text { xtranormal } \\
\text {.com? }\end{array}$ & $\begin{array}{l}\text { Xtranormal.com is a website that lets you direct your own } \\
\text { video by simply typing a script into its system. You can } \\
\text { adjust characters, gestures, camera angles and much } \\
\text { more. }\end{array}$ \\
\hline $\begin{array}{l}\text { Where can } \\
\text { I find a } \\
\text { tutorial } \\
\text { video? }\end{array}$ & $\begin{array}{l}\text { http://www.youtube.com/watch?v=IScD_oBw16c\&feature } \\
=\text { channel_video_title }\end{array}$ \\
\hline $\begin{array}{l}\text { What do I } \\
\text { need to } \\
\text { sign up? }\end{array}$ & - A working email address \\
\hline $\begin{array}{l}\text { How do I } \\
\text { sign up? }\end{array}$ & $\begin{array}{l}\text { 8. In the top right corner of the website, click on "create } \\
\text { account". } \\
\text { 9. You can either login with a variety of account providers, } \\
\text { such as google, facebook or twitter, or you can fill out the } \\
\text { form on the right side. } \\
\text { 10. Check your email inbox to activate your free trial account. } \\
\text { 11. You can now create one xtranormal video with the trail. } \\
\text { Remember that you can only publish one video per } \\
\text { account. Also, some content may not be free. }\end{array}$ \\
\hline $\begin{array}{l}\text { What can I } \\
\text { use } \\
\text { xtranormal } \\
\text {.com for? }\end{array}$ & $\begin{array}{l}\text { - You can direct your own movie. } \\
\text { - You can introduce topics. } \\
\text { - You can tell a story. } \\
\text { - You can do anything text and pictures can tell. }\end{array}$ \\
\hline $\begin{array}{l}\text { How do I } \\
\text { create a } \\
\text { video with } \\
\text { xtranormal } \\
\text {.com? }\end{array}$ & $\begin{array}{l}\text { 8. Sign into your account } \\
\text { 9. Choose "make movies" from the top screen and then select } \\
\text { a Showpak from the options. Use two or more actors to } \\
\text { make your movie a conversation. } \\
\text { 10. Chose a set. Make sure you use a free set. } \\
\text { 11. Click on "actors" and chose your actors. } \\
\text { 12. In the actors menu, make sure to set the language in which }\end{array}$ \\
\hline
\end{tabular}




\begin{tabular}{|c|c|}
\hline & $\begin{array}{l}\text { 13. The "Sounds" tab lets you select background sound or } \\
\text { music. } \\
\text { 14. In the story tab, type in a script and put it in the mouths of } \\
\text { your characters. Using the + button at the bottom of the } \\
\text { dialog box will add another block of dialog for the second } \\
\text { actor. Xtranormal does not know special characters. } \\
\text { 15. You can set the character on top of the script boxes. } \\
\text { 16. On the right side you can save your work and come back } \\
\text { later. You can also preview your video or listen to the } \\
\text { dialogue. } \\
\text { 17. Add expressions and actions by clicking and dragging the } \\
\text { action icons along the left hand side of the editing box into } \\
\text { the script at the appropriate places. Once you have placed } \\
\text { the icon in the script, you will be given a list of actions or } \\
\text { expressions to choose from. Click "apply" when you have } \\
\text { highlighted the one you want to use. Remember that the } \\
\text { actions and gestures you choose should help the viewer } \\
\text { understand and enjoy the movie. They should also } \\
\text { resemble to what your characters are saying at that time. } \\
\text { 18. Set your camera to "Auto camera" if you do not want to } \\
\text { setup camera moves. } \\
\text { 19. 10.When you have finished typing the script, gave your } \\
\text { directions and made all the changes you would like, click } \\
\text { the "Publish" button and preview your movie. } \\
\text { 20. Give your video a title and a description. } \\
\text { 21. Share the address with the class. }\end{array}$ \\
\hline Hints & $\begin{array}{l}\text { - If you cannot publish the video, it means that you might } \\
\text { have used too much costly content and have gone over the } \\
\text { limit of your trial account. In this case consider using } \\
\text { cheaper elements. } \\
\text { - Do not drag emotions or actions into the middle of a word } \\
\text { or the word will be torn apart. } \\
\text { - Do not forget to set the language or otherwise the } \\
\text { characters will have strong accents and you will not be able } \\
\text { to understand them. }\end{array}$ \\
\hline
\end{tabular}


After your trip to Dresden, you are inspired to tell your friends about the city of Dresden. You figure that creating an advertisement video about the city would be a good way to convey your message. Use xtranormal to tell a story about the city of Dresden. You are free to choose about details like what to highlight and how to tell it. The important factor is that your peers at home get to know the city.

- Use at least two characters in the video.

- Give information about at least two sights in Dresden or culturally interesting aspects of the city that you have come across in the past unit.

- Be creative about how your characters interact. By incorporating emotions and character moves, the video becomes more vivid and interesting to your peers.

After you created the movie, create a short quiz on the movie that contains at least five questions about your movie. That way your friends at home can make sure, that they understood key points in the movie.

Send the link to the movie and five quiz questions to your instructor in an email. 
Appendix C: IPA Assessment for thematic unit 
Name:

Lies den Text und beantworte die Fragen dazu!

\section{Stadtführer „Wien“}

Wien gehört zu den schönsten Städten auf der Welt. In Wien haben nicht nur viele Herrscher und ihre Familien residiert, sondern auch viele Berühmtheiten aus Kultur, Geschichte und Wissenschaft gelebt. Die Stadt Wien verbindet man meist mit der Donau. Seit der Donauregulierung im 19. Jahrhundert, ist der Fluss jedoch von der Stadt getrennt worden. Rund um die 1979 eröffnete UNO-City, hat sich das neue Wien die Donau zurückbekommen. Das so entstandene Erholungsgebiet an der Neuen Donau, welches bekannt ist für seine Sport- und Freizeit- und Erholungsmöglichkeiten, macht es zu einem attraktiven Platz in Wien.

Wien ist recht untypisch für eine Großstadt. Hier gibt es wenig neue, moderne Gebäude, sondern viele alte Gebäude. Altbauten prägen das Stadtbild. Moderne Architektur hat fast keinen Einfluss darauf.

Der Stephansplatz ist für viele Touristen ein guter Ausgangspunkt. Hier steht nicht nur der Stephansdom, von hier aus kann man auch eine Kutschen(Fiaker)-Fahrt durch die barocke Innenstadt von Wien unternehmen. Von hier lassen sich auch alle wichtigen Sehenswürdigkeiten zu Fuß erreichen. Der sogenannte Graben ist eine der vielen Fußgängerzonen in der Nähe des Stephansplatzes. Hier gibt es viele berühmte Straßencafés, die zu einer Pause einladen. Dort steht auch die barocke Pestsäule aus dem Jahr 1679. Mitten im Stadtzentrum ist die Kärntnerstraße, in der es nicht nur Touristen-Läden gibt, ist genauso wie der Graben für eine Shopping-Tour geeignet. Der Stephansdom(Bild oben) ist eine der schönsten gotischen Kathedralen der Welt und das Wahrzeichen Wiens.

from: http://www.ilsehruby.at/wien.html

1. What is the name of the famous river in Vienna (auf Deutsch)? (1 Punkt)

2. According to the article, what is the architecture of Vienna like? (3 Punkte)

3. What famous building can be found at Stephansplatz? What type of building is it? (2 Punkte)

4. Where in Vienna is der Graben located? What is it? (2 Punkte)

5. What things does one find there? (Name one tourist attraction/thing to do). (2 Punkte)

6. Where is the Kärntnerstraße located? What is it renowned for? Mention at least two things.

\section{(3 Punkte)}


You and your partner will act out spontaneously the following scenario. Use the points to guide your conversation. Each partner should talk for the same amount of time. The entire conversation should last 5-6 minutes.

You and your partner are traveling through Europe on a Eurail pass. You have two days to spend in Vienna (Wien) and have to decide what you would like to see in the city. Discuss with your partner the following:

You and your friend are not in total agreement about what you would like to do. You get out of a taxi at the "Museums quartier" and would like to see as much as possible as you just have 2 days in Vienna. Your hostel is next to the Watch and "Burgh Theater". Decide what way you want to walk there, so that you see as much as possible on the way. Look at the map and explain to your partner which way you would take and what you would see/pass on your way there. What other sights are near the ones you would like to see?

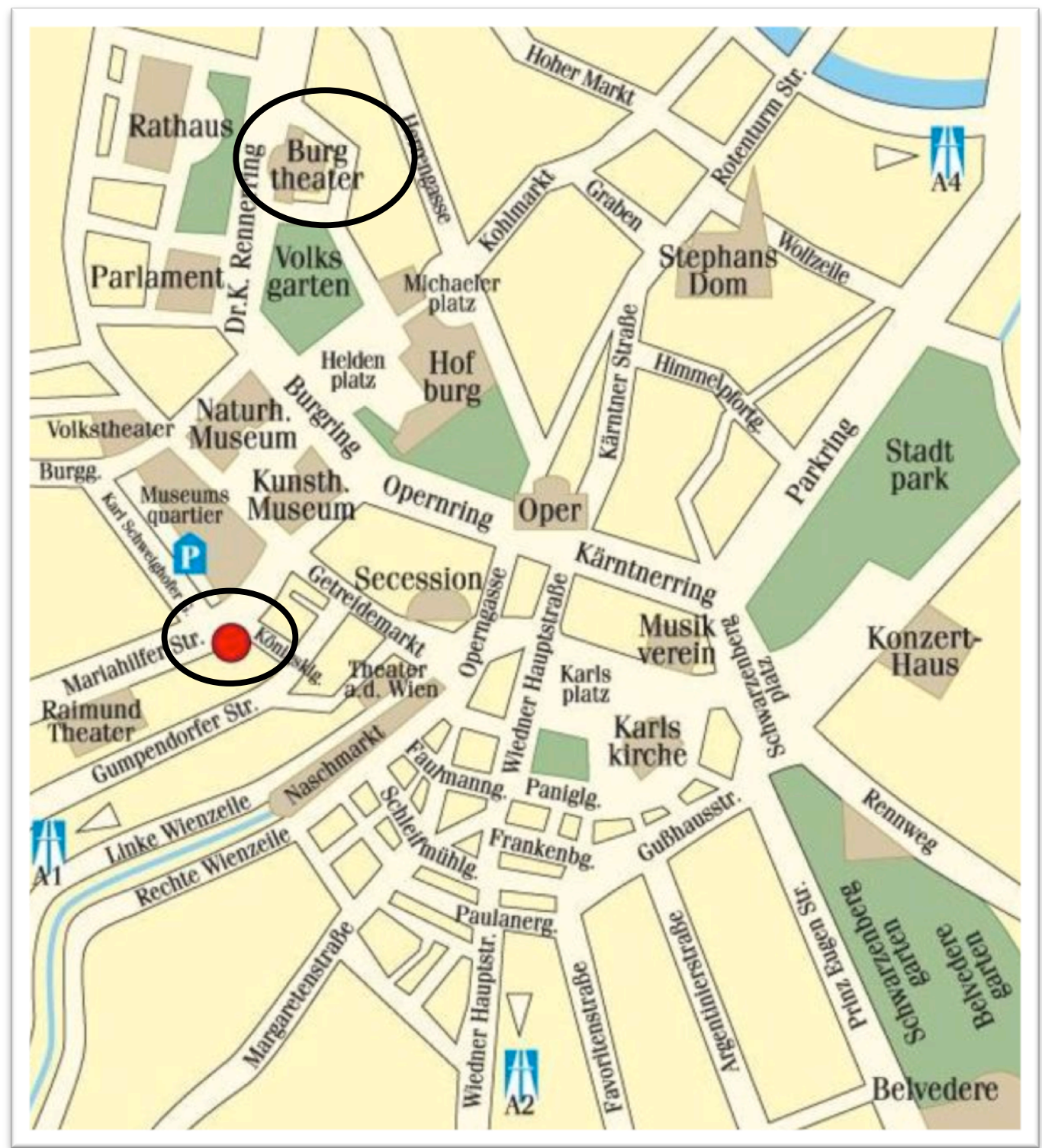

Source: http://www.das-tyrol.at/de/lage. 1 


\section{Topic: A year in Germany}

You are on a student exchange for Germany and you want to write a blog entry about the city you have now been living in for a year. You want to let your friends at home know what the city is like, what sights it has and how your life in Germany is. Think about the following aspects while you are writing the first blog entry:

- In which city do you live?

- What have you seen in this city? (Which sights?)

- What did you especially like? What did you not like about the city?

- Is there another city close by which you would like to visit? How would you get there? What do you want to do there?

\section{Organization}

Please hand in 100 words, typed and double-spaced.

\section{Possible outline}

- Title fort he blog entry

- Introduction: Which aspects are important for you and why? What is your personal connection tot he topic?

- Main part: Discuss the topics above and introduce their advantages and disadvantages.

- Conclusion: Finish your essay with a concluding sentence or paragraph

\section{Hints:}

- Pay close attention to spelling and grammar.

- Read your essay at least twice before you hand it in.

- Correct your errors.

- Pay attention to time, sentence-structure, adjective endings etc. 
Appendix D: Rubrics for IPA interpersonal and presentational

The rubrics presented to grade the IPA interpersonal and presentational assessment are based on the Rubric found in Shrum and Glisan (2010, p. 493). 


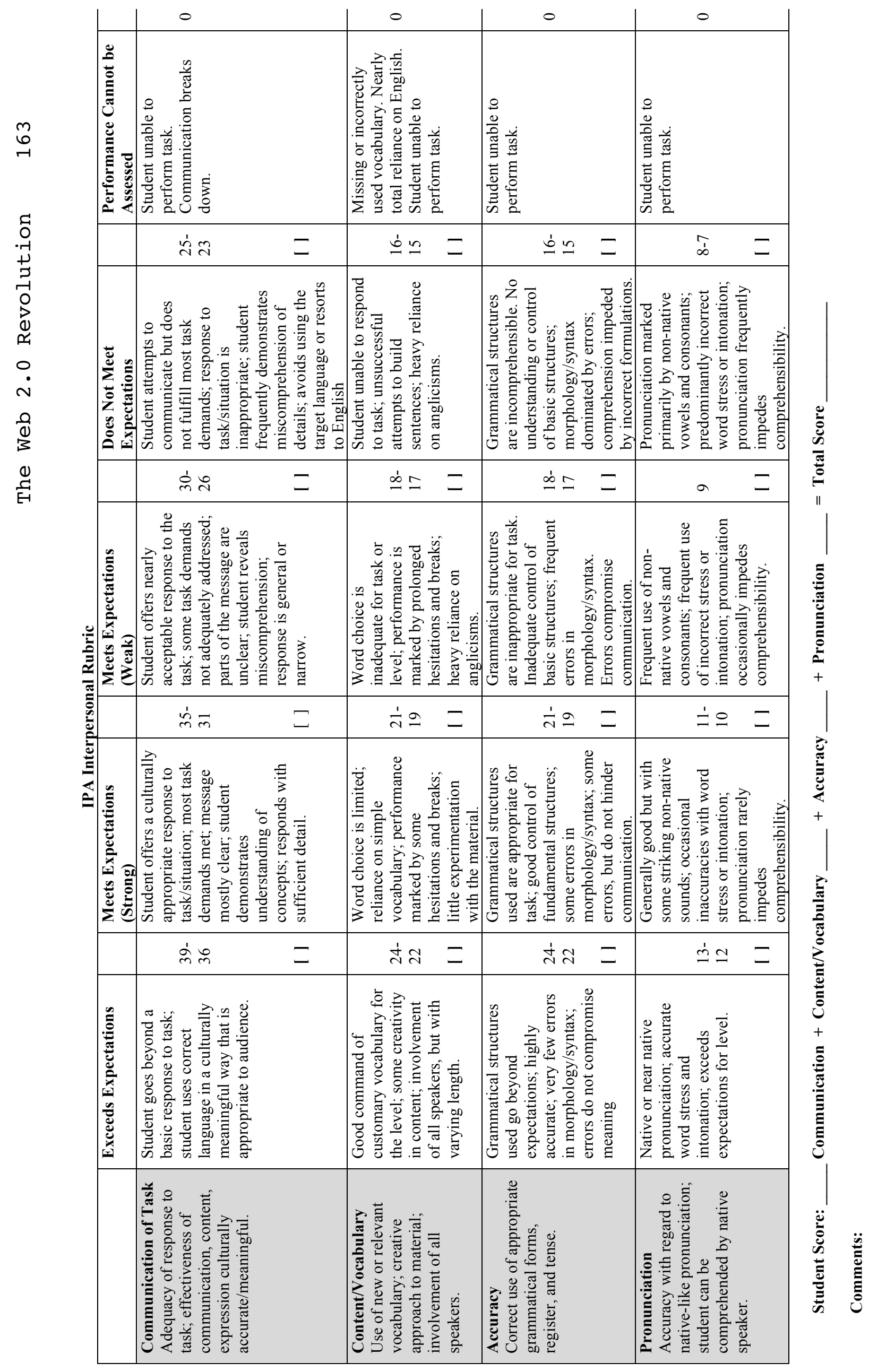


Appendix E: The five Cs

\section{STANDARDS FOR FOREIGN LANGUAGE LEARNING}

COMMUNICATION

Communicate in Languages Other Than English

- Standard 1.1: Students engage in conversations, provide and obtain information, express feelings and emotions, and exchange opinions

- Standard 1.2: Students understand and interpret written and spoken language on a variety of topics

- Standard 1.3: Students present information, concepts, and ideas to an audience of listeners or readers on a variety of topics.

CULTURES

Gain Knowledge and Understanding of Other Cultures

- $\quad$ Standard 2.1: Students demonstrate an understanding of the relationship between the practices and perspectives of the culture studied

- Standard 2.2: Students demonstrate an understanding of the relationship between the products and perspectives of the culture studied

CONNECTIONS

Connect with Other Disciplines and Acquire Information

- Standard 3.1: Students reinforce and further their knowledge of other disciplines through the foreign language

- Standard 3.2: Students acquire information and recognize the distinctive viewpoints that are only available through the foreign language and its cultures

\section{COMPARISONS}

Develop Insight into the Nature of Language and Culture

- $\quad$ Standard 4.1: Students demonstrate understanding of the nature of language through comparisons of the language studied and their own

- Standard 4.2: Students demonstrate understanding of the concept of culture through comparisons of the cultures studied and their own.

\section{COMMUNITIES}

Participate in Multilingual Communities at Home \& Around the World

- Standard 5.1: Students use the language both within and beyond the school setting

- Standard 5.2: Students show evidence of becoming life-long learners by using the language for personal enjoyment and enrichment.

from

http: //www .yearoflanguages.org/i4a/pages/index . cfm?pageid=3392

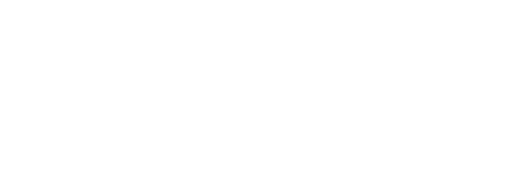

